\title{
Adventures in Defining Roles of Oxygenases in the Regulation of Protein Biosynthesis
}

Louise J. Walport, ${ }^{[a]}$ Christopher J. Schofield*[a]
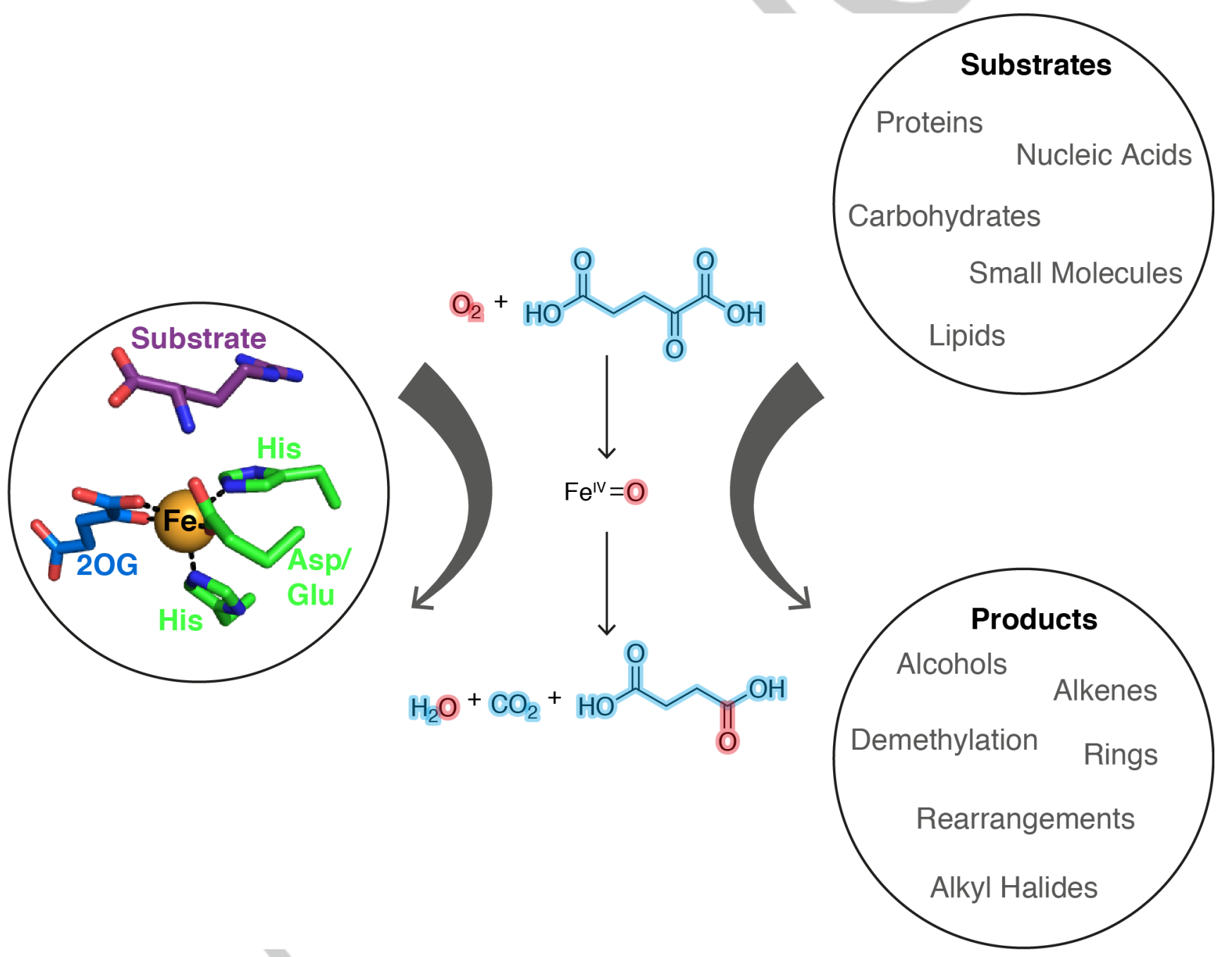
Abstract: The 2-oxoglutarate (2OG) dependent oxygenases were first identified as having roles in the post-translational modification of procollagen in animals. Subsequently in plants and microbes, they were shown to have roles in the biosynthesis of many secondary metabolites, including signalling molecules and the penicillin/cephalosporin antibiotics. Crystallographic studies of microbial $20 \mathrm{O}$ oxygenases and related enzymes, coupled to DNA sequence analyses, led to the prediction that $2 \mathrm{OG}$ oxygenases are widely distributed in aerobic biology. This personal account begins with examples of the roles of $20 \mathrm{G}$ oxygenases in antibiotic biosynthesis, and then describes efforts to assign functions to other predicted 2OG oxygenases. In humans, $20 \mathrm{O}$ oxygenases have been found to have roles in metabolism, as well as in the epigenetic regulation of protein and nucleic acid biosynthesis and function. The roles and functions of human $20 \mathrm{O}$ oxygenases are compared, focussing on discussion of their substrate and product selectivities. The account aims to emphasize how scoping the substrate selectivity of, sometimes promiscuous, enzymes can provide insights into their functions and so enable therapeutic work.

\section{Identification of the 2-oxoglutarate oxygenases}

Ferrous iron and 2-oxoglutarate (2OG) oxygenases were first identified in studies on post-translational modifications to procollagens, the precursor proteins of the extracellular collagens. ${ }^{[1]}$ Work by Henry Dakin, long before, had provided evidence for the reaction of protein with atmospheric dioxygen; ${ }^{[2]}$ however, the work on procollagen modifications was pioneering in identifying enzymes that catalyse the direct reaction of proteins with dioxygen. The first such identified enzymes were the procollagen prolyl-4-hydroxylases (CP4Hs), with the procollagen prolyl-3-hydroxylases (CP3Hs) and procollagen lysyl hydroxylases (PLODs) subsequently being discovered (Figure 1). ${ }^{[1]}$

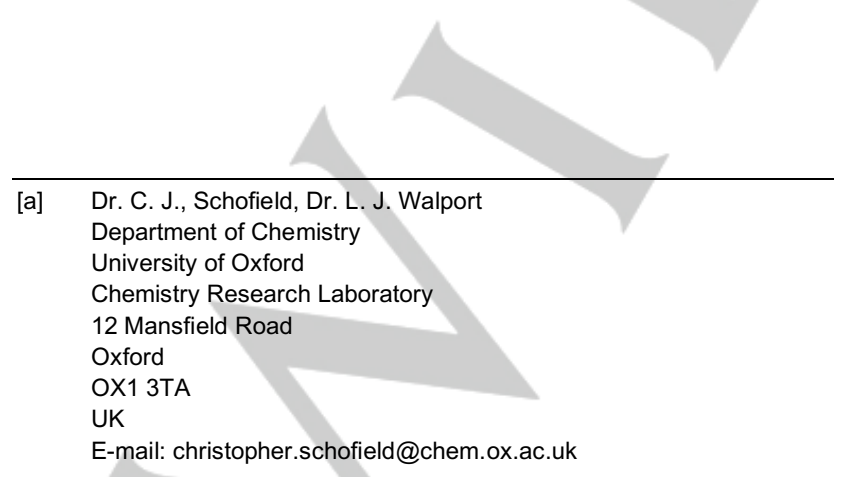

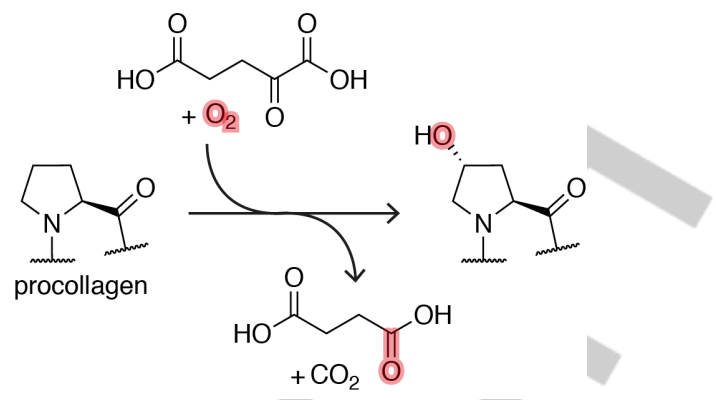

Figure 1. A typical 2-oxoglutarate oxygenase catalysed reaction shown for procollagen trans-prolyl-4-hydroxylation, as catalysed by collagen prolyl-4hydroxylase $(\mathrm{CP} 4 \mathrm{H})$, which, like other $20 \mathrm{G}$ oxygenases, is dependent on $\mathrm{Fe}$ (II) for catalysis. Cis-prolyl-3-hydroxylation and lysyl-5R-hydroxylation also occur during collagen biosynthesis.

In a parallel line of investigation, work led by Hayaishi identified oxygenases that are mechanistically related to the $20 \mathrm{O}$ oxygenases, but which act on small molecule substrates, including catechols. ${ }^{[3]}$ In a third line of investigation, directly leading to our own work, studies on the biosynthetic origins of the $\beta$-lactam ring-containing penicillin antibacterials, had shown that the immediate precursors of the penicillins were peptides requiring oxidative modification in order to produce the fused bicyclic $\beta$-lactam-thiazolidine heterocyclic core of the penicillins. ${ }^{[4-}$ ${ }^{6]}$ A single oxidase, isopenicillin $\mathrm{N}$ synthase (IPNS), subsequently shown to be structurally related to the $20 \mathrm{G}$ oxygenases, was shown to catalyse formation of isopenicillin $\mathrm{N}$ from the tripeptide $\delta$-(L)- $\alpha$-aminodipoyl-(L)-cystenyl-(D)-valine in a single step (Figure 2). ${ }^{[4-6]}$

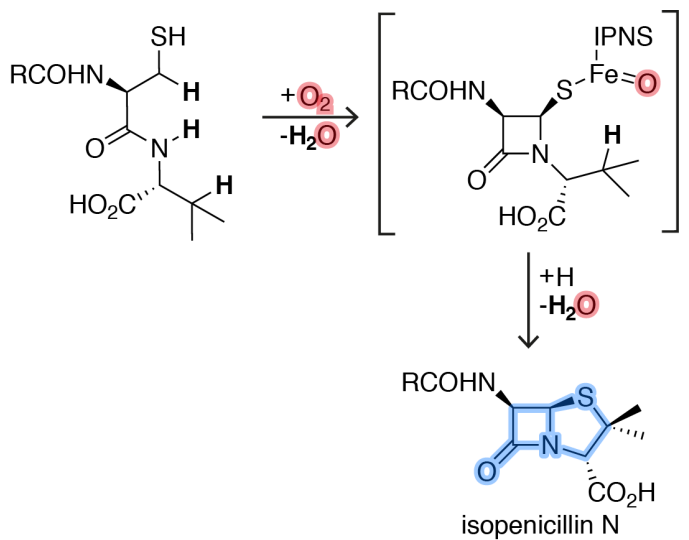

Figure 2. The isopenicillin $N$ synthase (IPNS) reaction showing the enzyme bound $\mathrm{Fe}=\mathrm{O}$ intermediate. Note that unlike the canonical 2OG oxygenases, IPNS does not use $20 \mathrm{OG}$ as a cosubstrate, instead catalysing the four electron oxidation of its peptide substrate. $R=\delta$-(L)- $\alpha$-aminodipoyl. The fused bicyclic $\beta$ lactam-thiazolidine heterocyclic core of the penicillins is highlighted in blue. 
Isopenicillin $\mathrm{N}$ is a branch-point intermediate which is involved in the biosynthesis of all penicillins and cephalosporins. ${ }^{[7]}$ In some microorganisms isopenicillin $\mathrm{N}$ is epimerised to give penicillin $\mathrm{N}$, the substrate for the $20 \mathrm{O}$ oxygenase deacetoxycephalosporin- $C$ synthase (DAOCS). DAOCS catalyses the oxidative ring expansion of penicillin $\mathrm{N}$ giving deacetoxycephalosporin- $\mathrm{C}$ (DAOC), in a reaction likely proceeding via abstraction of a hydrogen atom from a penicillin methyl group, followed by oxidative rearrangement and desaturation (Figure 3). The conversion of DAOC to deacetylcephalosporin-C (DAC) is catalysed by deacetylcephalosporin-C synthase (DACS). DACS is also a $20 \mathrm{OG}$ oxygenase, as are other oxygenases catalysing subsequent steps in cephalosporin biosynthesis including the C7 a-hydroxylation step en route to the cephamycins ${ }^{[7,8]}$<smiles>CCONC1C(=O)N2S[C@@H]1[C@@H](O)[C@@H](C)C2C(=O)O</smiles>
penicillin $\mathrm{N}$<smiles>CC(=O)NC1C(=O)N2C(C(=O)O)=C(C)CSC12</smiles>

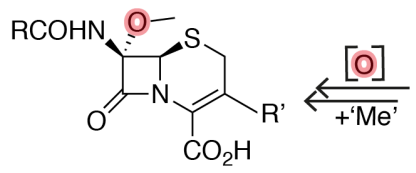
cephamycins<smiles>CCCCCCCOc1ccccc1</smiles><smiles>O=C(O)C1=C(CO)CS[C@@H]2C(O)C(=O)N12</smiles>

dioxide. Following various alternatives, a perceptive mechanistic proposal was made by Hanauske-Abel and Günzler; ${ }^{[13]}$ this has been elaborated on, but largely validated, by subsequent spectroscopic, structural, and kinetic studies. ${ }^{[12,14]}$

In summary, in the $20 \mathrm{O}$ oxygenases a single ferrous iron is bound by two or, more commonly, three protein ligands comprising an $\mathrm{HXD} / \mathrm{E} \ldots . \mathrm{H}$ triad. $2 \mathrm{OG}$ binds bidentately to the metal via its oxalyl group with its $\mathrm{C}-5$ carboxylate being held in place by a basic (Lys/Arg) residue and, normally, at least one more polar residue. ${ }^{[15,16]}$ Substrate binding at the active site (normally) precipitates loss of a metal bound water, enabling binding of dioxygen. Oxidative decarboxylation, likely via (a) peroxide intermediate(s), ${ }^{[17]}$ yields an $\mathrm{Fe}^{\mathrm{IV}}=\mathrm{O}$ species that, at least normally, is responsible for the two electron oxidation of substrates (Figure 4).

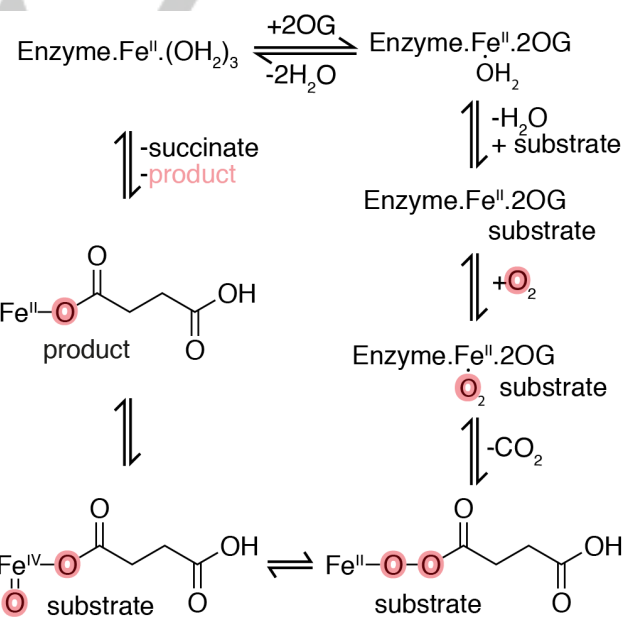

Figure 4. Outline consensus mechanism for the $20 \mathrm{G}$ oxygenases. Variations on this may occur (e.g. other peroxide intermediates). The enzyme normally ligates the $\mathrm{Fe}$ in an octahedral manner via a conserved 2-His-1-carboxylate triad of residues.

IPNS has a different, but related mechanism to the typical 2OG oxygenases. ${ }^{[6,18]}$ Ring closure to the core penicillin nucleus occurs in a stepwise manner with the formation of an enzyme-bound monocyclic $\beta$-lactam intermediate linked to an $\mathrm{Fe}^{\mathrm{IV}}=\mathrm{O}$ species. This process is analogous to the oxidative decarboxylation of $20 \mathrm{O}$ to give carbon dioxide and the $\mathrm{Fe}^{\mathrm{I}}=\mathrm{O}$ succinate complex in typical $20 \mathrm{OG}$ oxygenase catalysis. ${ }^{[5,19]}$ In the case of IPNS, the $\mathrm{Fe}^{\mathrm{IV}}=\mathrm{O}$ species mediates ring closure to give the thiazolidine of isopenicillin $\mathrm{N}$ (Figure 2). 
Variations on the common $20 \mathrm{O}$ oxygenase mechanism can occur, e.g. one interesting enzyme from Pseudomonas spp. catalyses the oxidative fragmentation of $20 \mathrm{O}$ to give ethylene in a Grobtype fragmentation reaction (Figure $5 A$ ). ${ }^{[20,21]}$ The precise nature of $20 \mathrm{O}$ binding is proposed to determine whether oxidative fragmentation to give succinate (which is apparently coupled to arginine oxidation) or fragmentation to ethylene occurs (Figure $5 A$ ). Ethylene formation is also catalysed by the plant enzyme 1aminocyclopropane-1-carboxylic acid (ACC) oxidase, which like IPNS is structurally related to the $20 \mathrm{G}$ oxygenases, but which does not employ $20 \mathrm{OG}$ as a co-substrate. ${ }^{[22-24]}$ ACC oxidase (ACCO) catalyses conversion of ACC into ethylene, carbon dioxide and cyanide, in a manner dependent on carbon dioxide (or bicarbonate) and, likely ascorbate (Figure 5B). Ethylene has a crucial role in many aspects of plant biology, including stress responses and signalling. ${ }^{[25]}$ The role of ACCO in stress responses was a harbinger of the roles of $20 \mathrm{O}$ oxygenases in signalling and stress responses in animals (see below).

A

$\overbrace{\mathrm{O}}^{\text {(2OG }} \stackrel{\text { PsEFE }}{\longrightarrow}$

B

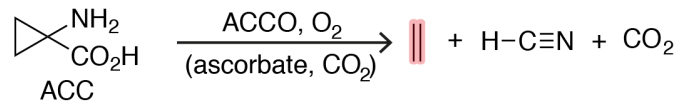

Figure 5. Mechanisms of ethylene production by $20 \mathrm{G}$ family enzymes (A) Grobtype oxidative fragmentation of $20 \mathrm{OG}$ by Pseudomonas syringae pv. phaseolicola ethylene-forming enzyme (PsEFE). The reaction uses arginine, producing guanidine and pyrroline-5-carboxylate (P5C) as 'co-products'. See refs 20 and 21 for results on stoichiometry of the reaction. (B) ACC oxidase catalyses the production of ethylene from 1-amino-cyclopropane-1-carboxylic acid (ACC).

\section{Reactions of $20 \mathrm{G}$ oxygenases}

The reactions of IPNS and DAOCS announced the potential of $20 \mathrm{OG}$ oxygenases and related enzymes to catalyse reactions other than simple additions of oxygen atoms, as occurs, for example, in procollagen hydroxylation and in the identified reactions of $20 \mathrm{OG}$ oxygenases in animals. ${ }^{[6,7,71]}$ Studies on the $\beta$ lactam biosynthesis oxygenases/IPNS, and, to a lesser extent, the collagen prolyl hydroxylases, revealed the potential for promiscuity in $20 \mathrm{G}$ oxygenase/related oxidase catalysis. ${ }^{[26]}$ Thus, whilst in some microorganisms there is a bifunctional DAOCS/DACS, in others there are separate DAOCS and DACS enzymes, each with low levels of the 'other' activity. ${ }^{[27-31]}$ Further, the conversion of penicillin $\mathrm{N}$ to DAOC is accompanied by the production of a tertiary alcohol 'shunt' product and DAC can be further oxidised to an aldehyde. ${ }^{[32]}$ Substrate analogue studies on DAOCS, as well as structural insights, are helping to enable improved fermentation procedures for the production of clinically useful cephalosporins. ${ }^{[7]}$

The ability of $20 \mathrm{OG}$ oxygenases to accept different types of substrates and produce different types of products is nicely illustrated by the three reactions catalysed by clavaminic acid synthase (CAS) during biosynthesis of the clinically important $\beta$ lactamase inhibitor, clavulanic acid (Figure 6)..$^{[7,11,33-35]}$ Initially, CAS catalyses a typical $20 \mathrm{O}$ oxygenase reaction, i.e. hydroxylation of a monocyclic $\beta$-lactam. Another enzyme, then catalyses hydrolysis of the guanidino side chain of the first CAS product to give the amine of proclavaminic acid. ${ }^{[36]}$ The latter then undergoes two further CAS-catalysed reactions, i.e. oxidative bicyclisation followed by desaturation. More generally, these studies exemplify the capacity of (some) 2OG oxygenases to catalyse multiple reactions and for branching of pathways during catalysis by them. ${ }^{[34,37]}$ The ability of $2 \mathrm{OG}$ oxygenases to catalyse oxidations of methyl groups, as shown by the studies on cephalosporin and of gibberellin biosynthesis (in plants) has relevance to protein and nucleic acid group oxygenases involved in chromatin biology in eukaryotes (see below). There are now multiple examples of the relaxed substrate/product selectivities of $2 O G$ oxygenases, as well as for ACCO and IPNS. The ability of IPNS to convert tripeptide analogues of ACC to multiple bicyclic $\beta$-lactams is particularly striking, ${ }^{[7,38,39]}$ especially given the relative inaccessibility of many of these product types to nonenzymatic synthetic chemistry. 


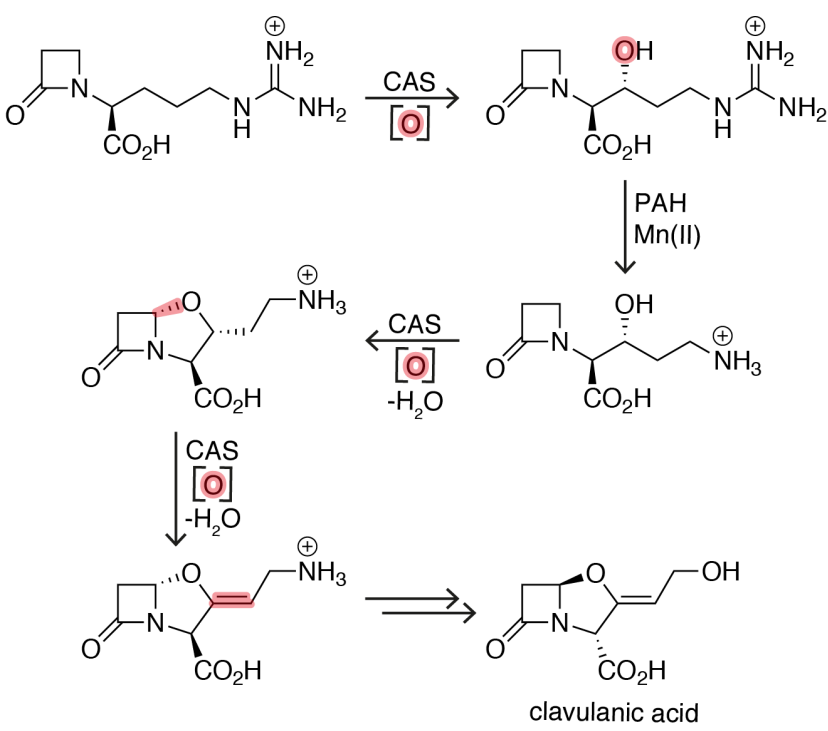

Figure 6. Trifunctional role of clavaminic acid synthase (CAS) in clavulanic acid biosynthesis. $[O]=20 \mathrm{O}$ oxygenase catalysed step coupled to conversion of $2 O G$ and dioxygen into succinate and carbon dioxide. PAS is proclavaminate amidinohydrolase.

The aforementioned studies on the oxygenases of collagen biosynthesis and microbial/plant secondary metabolism, helped to scope the remarkable range of $20 \mathrm{OG}$ oxygenase catalysis. Stereoselective hydroxylation was, and remains, a difficult challenge for synthetic chemistry. This coupled to the exotic nature of some $20 \mathrm{OG}$ oxygenase-catalysed reactions, has rendered them interesting from a synthetic chemistry perspective.

Crystallographic studies on microbial 2OG oxygenases identified a characteristic double stranded $\beta$-helix (DSBH) core protein fold, which supports $\mathrm{Fe}(\mathrm{II})$, cosubstrate and substrate binding (Figure 7). ${ }^{[10,40-43]}$ Unexpectedly, the structural studies on IPNS and related enzymes led to the proposal that many homologous enzymes are widely distributed, with some $60-70$ potential human members being identified. ${ }^{[42]}$ In the next sections we summarise work aiming to assign functions to these enzymes, some of which play key roles in the regulation of protein biosynthesis. Particular emphasis is placed on the (apparent) ability of some, but not all, of the human enzymes to accept multiple substrates. The roles of substrate analogue work/biochemical screening studies in helping to assign biological function, as well as their use as mechanistic probes is emphasized.
A

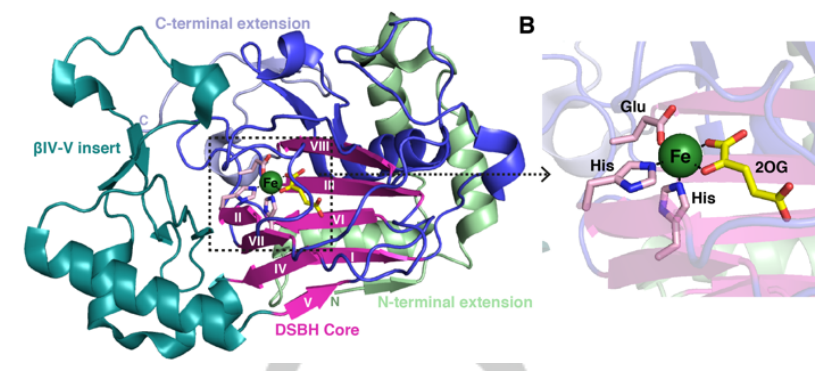

Figure 7. Overview of the canonical structure of $20 \mathrm{G}$ oxygenases. (A) Representation of the $20 \mathrm{O}$ oxygenase fold adapted from a crystal structure of CAS (PDB ID: 1DS1) ${ }^{[43]}$. The core distorted double-stranded beta-helix (DSBH) fold is in pink ( $\beta$-strand I-VIII). Elements surrounding this core are subfamily characteristic. (B) Insert showing the coordination of $\mathrm{Fe}(\mathrm{II})$ by a conserved triad of residues and the cosubstrate $20 \mathrm{OG}$.

\section{Functional assignment of 20G oxygenases in metabolism}

Our group's first concerted efforts on a human 2OG oxygenase concerned phytanoyl CoA hydroxylase $(\mathrm{PHYH}) .{ }^{[36,44,45]}$ Unlike pristanic acid, phytanic acid cannot undergo metabolism by the $\beta$ oxidation pathway, because it possesses a C-2 ( $\beta$ ) methyl group. ${ }^{[44]} \mathrm{PHYH}$ catalyses the $\mathrm{C}-2(\beta)$ hydroxylation of phytanoyl coenzyme $A$, a chlorophyll metabolite, in a peroxisomally located pathway (Figure $8 \mathrm{~A}$ ). The overall effect of the pathway is to excise the C-2 ( $\alpha$ ) methylene group of phytanic acid to give pristanic acid (as its coenzyme (CoA) derivative). Mutations to DNA coding for $\mathrm{PHYH}$, or to DNA encoding for other elements of the phytanic oxidation pathway, correlate with Refsum Disease, the symptoms of which result from accumulation of phytanic acid (derivatives). Refsum Disease is rare and is treated principally by patients avoiding chlorophyll in their diet. ${ }^{[44]}$

$\mathrm{PHYH}$ is interesting from a chemical perspective because it converts the $C-3(\beta)$ methyl substituted epimers of phytanoyl CoA into two different $\mathrm{C}-2(\alpha)$ hydroxylated diastereomers, providing another example of flexibility/stereoselectivity in 2OG oxygenase catalysis (Figure 8A). Both alcohol products of $\mathrm{PHYH}$ are subsequently converted into pristanal, by the action of a thiamine pyrophosphate dependent enzyme, which is then oxidised to pristanic acid. ${ }^{[44]}$ Substrate analogue studies in vitro suggest that $\mathrm{PHYH}$ may accept other $\beta$-methylated substrates that may be bound by carrier proteins. ${ }^{[44,46]}$ Crystallographic analyses reveal 
$\mathrm{PHYH}$ has the same core DSBH fold, and similar Fe(II) and 2OG binding elements, to those present in the bacterial 2OG oxygenases, but has subfamily distinct features. ${ }^{[36]}$

A<smiles>CC(C)CCC[C@@H](C)CCC[C@H](C)CCC[C@H](C)CC(=O)SCOCCO</smiles><smiles></smiles><smiles>[CH2]CCCC(C)C</smiles><smiles>CCCC</smiles><smiles>CC(C)CCC[C@H](C)CCC[C@H](C)CCC[C@H](C)C=O</smiles><smiles>CC(C)CCC[C@H](C)CCC[C@H](C)CCC[C@H](C)C(=O)O</smiles>

B<smiles>CCCCC(=O)C(=O)OCCCCCCCC(=O)C(=O)OC(=O)C(=O)O</smiles>

Figure 8. Phytanic acid metabolism. (A) Phytanoyl CoA hydroxylase (PHYH) catalyses the C-2 hydroxylation of phytanoyl coenzyme A. Note phytanic acid occurs naturally as a mixture of $\mathrm{C} 3$ diastereoisomers. $[\mathrm{O}]=2 \mathrm{OG}$ oxygenase catalysed step coupled to conversion of $20 \mathrm{G}$ and dioxygen into succinate and carbon dioxide. (B) Hydrophobic $20 \mathrm{G}$ analogues that can partially rescue the activity of some hydrophobic PHYH substitutions in the $20 \mathrm{G}$ binding pocket found in Refsum's disease patients. ${ }^{[4]}$

Whilst some of the clinically observed mutations to the PHYH gene likely encode for variants lacking catalytic activity, others manifest impaired levels of activity. ${ }^{[48]}$ Some of the substitutions occur at the sites of polar residues involved in binding the $20 \mathrm{G} \mathrm{C}$ 5 carboxylate. The activity of some such hydrophobic substitutions can be (partially) 'rescued' by the use of complementary hydrophobic $20 \mathrm{O}$ analogues (Figure 8B). ${ }^{[47]}$ Although such a concept likely has little utility in treatment of Refsum Disease (because of the variety of the mutations and treatment, and the success of the diet therapy), this work does raise the possibility of altering the cosubstrate selectivity of $20 \mathrm{O}$ oxygenases, other than by simple inhibition for therapeutic benefit.

Two 2OG oxygenases play critical indirect roles in fatty acid metabolism via catalysis of steps in the biosynthesis of carnitine, which is required for transport of fatty acids into mitochondria. ${ }^{[49]}$ The small molecule starting point for carnitine biosynthesis is $N^{\varepsilon}$ trimethyl lysine (TML) which is produced via protein degradation, likely substantially from $\mathrm{N}$-methylated histones. Trimethyllysine hydroxylase (TMLH) catalyses (3S)-hydroxylation of TML to give (2S,3S)-3-hydroxy- $N$-trimethyllysine, ${ }^{[50]}$ which undergoes transformation to $y$-butyrobetaine, which further undergoes $(3 R)$ hydroxylation as catalysed by $\mathrm{Y}$-butyrobetaine hydroxylase (BBOX) to give carnitine (Figure 9A). As an aside it is notable that the role of TML in the carnitine biosynthesis pathway provides a potentially direct link between histone modification status (and, hence, epigenetics) and fatty acid metabolism. The stereochemistry of the BBOX and TMLH catalysed reactions are conserved with respect to the $N^{\varepsilon}$-trimethyl- and carboxylate groups in their substrates, ${ }^{[50]}$ consistent with a common evolutionary origin. This proposal is supported by sequence analyses based on crystallographic studies on BBOX, which revealed a dimeric structure, ${ }^{[51]}$ and contrasts with the monomeric nature of IPNS/DAOCS subfamily oxygenases.

Substrate analogue studies on BBOX have provided insights into its selectivity. ${ }^{\left[{ }^{[1-53]}\right.}$ Notably, BBOX has been shown to accept the trimethylphosphine analogue of carnitine, as well as various cyclic carnitine analogues (Figure 9B). ${ }^{[53,54]}$ The latter work is of interest from the perspective of asymmetric catalysis by oxygenases, e.g. an achiral meso-cyclic analogue was shown to undergo BBOX catalysed desymmetrisation to give a product with 3 chiral centres in a single enzyme-catalysed step. ${ }^{[54]}$ BBOX is one of the proposed targets of the drug Meldonium, which is used for treatment of cardiovascular disease and which is proposed to be athletic 'performance enhancing' (Figure 9C). Meldonium is a BBOX substrate/competitive inhibitor undergoing oxidative fragmentation to produce products including formaldehyde, via a Stevens-type rearrangement. ${ }^{[55]}$ 


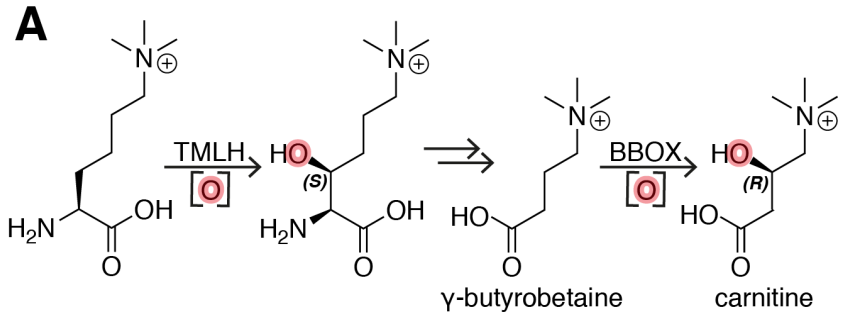

B<smiles>CC[N+]1(C)CC[C@@H](O)C(C(=O)O)C1</smiles>

C<smiles>CN1CC(CC(=O)O)CN1CC(=O)CC(N)CC(=O)O</smiles>

Figure 9. $20 \mathrm{O}$ oxygenases in carnitine biosynthesis. (A) Trimethyllysine hydroxylase $(T M L H)$ and $y$-butyrobetaine hydroxylase (BBOX) catalyse hydroxylation steps in the biosynthesis of carnitine. [O] $=20 \mathrm{G}$ oxygenase catalysed step coupled to conversion of $20 \mathrm{G}$ and dioxygen into succinate and carbon dioxide. (B) Substrate analogues accepted by BBOX. (C) Reaction of the BBOX substrate/competitive inhibitor, Meldonium, with BBOX.[51]

The aforementioned studies on 206 oxygenases involved in microbial and plant metabolism, as well as in fatty acid biosynthesis, provided our group with (bio)chemical and biophysical experience of this enzyme family. In particular they informed us that some 2OG oxygenases can manifest considerable promiscuity in terms of their substrate and product selectivities. This knowledge was to be important in our studies on $20 \mathrm{O}$ oxygenases in humans and other organisms that are involved in the regulation of transcription.

\section{5. $20 \mathrm{G}$ oxygenases in oxygen sensing}

In parallel with our group's work on the biochemistry and biophysics of $20 \mathrm{G}$ oxygenases, that of Peter Ratcliffe and Chris Pugh, also in Oxford, was working on the mechanisms that regulate the gene encoding for erythropoietin (EPO). EPO is a protein hormone, the presence of which stimulates formation of red blood cells. EPO is upregulated under hypoxic conditions, i.e. when dioxygen is limiting, e.g. at high altitude or with prolonged exercise.

The $\alpha, \beta$-heterodimeric hypoxia inducible (HIF) transcription factors had been identified as playing a dioxygen-regulated role in the regulation of the gene encoding for EPO. ${ }^{[56]}$ The levels of the $\beta$-subunit of HIF are not directly regulated by dioxygen availability (HIF- $\beta$ has the same sequence as the aryl hydrocarbon receptor nuclear translocator, ARNT). By contrast, levels of HIF- $\alpha$ isoforms, of which there are three in humans, are highly dependent on dioxygen availability. ${ }^{[56-58]}$ Under 'normoxic' conditions, i.e. when dioxygen availability is not limiting, HIF- $\alpha$ isoforms are rapidly degraded. Collaborative work between the Oxford groups, in parallel with work by Bill Kaelin and coworkers in the USA, demonstrated that post-translational prolylhydroxylation in either of two HIF- $\alpha$ dioxygen dependent degradation domains can signal for efficient HIF- $\alpha$ hydrolysis as mediated by the ubiquitin protease system. ${ }^{[59-61]}$ Thus, prolylhydroxylated HIF- $\alpha$ isoforms bind tightly to the von Hippel Lindau protein (VHL), which is a targeting domain for a ubiquitin E3 ligase. ${ }^{[62,63]}$ Non prolyl hydroxylated HIF- $\alpha$ binds much less tightly to $\mathrm{VHL}$, hence is very substantially more stable than prolylhydroxylated HIF- $\alpha$.

Combined biochemical, cellular and genetic studies led to the assignment of the HIF prolyl hydroxylases as $20 \mathrm{G}$ dependent oxygenases (Figure 10A). ${ }^{[61]}$ There are three human HIF prolyl hydroxylases (PHD1-3, for prolyl hydroxylase domain enzymes; or EGLN1-3). ${ }^{[64-66]}$ Importantly, there is evidence that the kinetic properties of the PHDs, both in isolated form and in cells, are consistent with their assignment as hypoxia/dioxygen sensors. ${ }^{[67-}$ ${ }^{69]}$ Indeed, at least PHD2, likely the most important/conserved of the human PHDs, appears to be very sensitive to variations in dioxygen availability, compared to that of $\mathrm{Fe}(\mathrm{II})$ and 2OG. ${ }^{[70]}$ Thus, detailed kinetic and biophysical analyses on PHD2 have shown that it manifests an unusually slow reaction with dioxygen. ${ }^{[68,71]}$ Whilst this property is not necessarily essential for prolyl hydroxylation activity to be limited by dioxygen availability in a cellular context (where factors including relative concentrations/locations can come into play) it is at least one that could be useful in this regard. Other properties of the PHDs also appear to be consistent with a major role for them in dioxygen concentration sensing; they form unusually stable complexes with ferrous iron and 2OG, with very little substrate uncoupled turnover 
of 2OG. ${ }^{[70,72]}$ However, that is not to say that in some circumstances the activities of the PHDs cannot be regulated by ferrous iron or $20 \mathrm{OG}$ availability, or that there are not other biologically relevant nuances to their catalysis. For example the three human PHDs manifest different selectivities for the two prolyl-hydroxylation sites in HIF- $\alpha$ isoforms. ${ }^{[57,59-61,73]}$ We have also recently found that binding of $2 \mathrm{OG}$ to the PHD2.Fe(II) complex hinders binding of prolyl-hydroxylated, but not non prolylhydroxylated (i.e. substrate), HIF- $\alpha$ to its active site. ${ }^{[4]}$ Studies on the evolution of the HIF system have indicated that the HIF-PHDVHL 'triad' extends across all, or near all, animals. ${ }^{[75]}$ Moreover, the proposed key biochemical properties of the system appear to be highly conserved, including with regard to the unusual catalytic properties of the PHDs (at least PHD2) and the effect of HIF-a prolyl hydroxylation on increasing the strength of HIF- $\alpha$ binding to VHL (as shown by work on the PHD/HIF system in Trichoplax adhaerens, the simplest known animal) ${ }^{[75]}$

A<smiles>CCC(=O)C1C[C@@H](O)CN1CCOc1ccccc1</smiles>

$\mathbf{B}$<smiles>CCNC1CC(=O)NC(C)C1=O</smiles>

C<smiles>CC(C)N[C@H]1C(=O)C(C)OC(=O)[C@@H]1O</smiles><smiles>CCCC(=O)C(NC(C)C)[C@@H](O)C(C)C</smiles><smiles></smiles>

Figure 10. Hydroxylation reactions involved in dioxygen sensing in animals. (A) Prolyl hydroxylation as catalysed by the HIF prolyl hydroxylases (human PHD1/2/3). (B) The promiscuous HIF- $\alpha$ hydroxylase, factor inhibiting HIF (FIH), catalyses $\mathrm{C}-3$ hydroxylation of an asparagine residue in HIF- $\alpha$ isoforms, as well as catalysing hydroxylation of asparagine residues, and (C) other residues, in ankyrin repeat domain proteins. $[\mathrm{O}]=2 \mathrm{OG}$ oxygenase catalysed step coupled to conversion of $2 \mathrm{OG}$ and dioxygen into succinate and carbon dioxide.

Importantly, HIF (and the PHDs) were found not only to regulate expression of the EPO gene, but also of hundreds of other genes in humans (and other animals) many of which work to ameliorate the effects of hypoxia. The precise sets of target genes expressed vary in a cell type/environment context-dependent manner. ${ }^{[58,61,76]}$ The assignment of the roles of the PHDs in the hypoxic response via transcriptional regulation was important, including because (i) it defined a new mechanism of enzyme-mediated transcriptional regulation that was directly linked to a response of major physiological importance; (ii) it opened up new therapeutic possibilities for the treatment of hypoxia-related diseases, including cancer and anaemia; ${ }^{[77,78]}$ and (iii) it led to the proposal that the kinetic/biophysical properties of the enzymes involved are directly linked to their sensing roles.

A second type of $20 \mathrm{O}$ oxygenase mediated modification to HIF$\alpha$ was subsequently shown to play an important role in the hypoxic response. ${ }^{[79]}$ Thus, factor inhibiting HIF (FIH) catalyses hydroxylation of an asparaginyl residue located in the $C$-terminal transcriptional activation domain (CAD) of HIF- $\alpha$ isoforms (Figure 10B). ${ }^{[80-83]}$ This hydroxylation serves to reduce the interaction of HIF with CBP/p300 proteins, which are 'transcriptional activators' (they are multi-domain proteins with histone acetyltransferase activity). Just like the substantial positive effect of HIF- $\alpha$ prolyl hydroxylation on binding to $\mathrm{VHL}$, but in the opposite direction, that of CAD asparaginyl hydroxylation has a substantial negative effect on binding of HIF to $\mathrm{CBP} / \mathrm{p} 300$, likely via disrupting a hydrophobic binding element. ${ }^{[81]}$ At least in some cellular contexts $\mathrm{FIH}$ appears to be more active at lower dioxygen concentrations than the PHDs, consistent with its kinetic properties in isolated form. ${ }^{[67,84]}$ The extent to which FIH activity impacts on HIF target gene expression is context-dependent, as shown by our studies employing selective $\mathrm{PHD} / \mathrm{FIH}$ small molecule inhibitors (developed on the basis of mechanistic considerations and crystallographic studies) ${ }^{[85]}$, in conjunction with 'genetic intervention' methods. ${ }^{[86-88]}$ Following from initial studies demonstrating that catalytically inactive $20 \mathrm{G}$ analogues/competitors and iron chelators can act as PHD (and $\mathrm{FIH}$ ) inhibitors, more selective PHD inhibitors are being developed for clinical applications. ${ }^{[78,85,89,90]}$ The most advanced such compounds are PHD inhibitors for the treatment of anaemia in patients with chronic kidney disease, via HIF- $\alpha$ mediated erythropoietin (EPO) upregulation (as an alternative to the use of protein therapy using EPO). ${ }^{[78,91,92]}$

PHD inhibition has potential for use in other therapeutic applications, including wound healing, stroke and sickle cell anaemia, and downregulation of HIF activity has potential for cancer treatment, because many tumours are apparently hypoxic. ${ }^{[93,94]}$ It's important to note, however, that the various HIF 
'isoforms' regulate different, sometimes overlapping gene sets, with the sets that are upregulated depending on the context (e.g. cell/tissue-type, developmental stage, environmental chemistry). Thus, obtaining 'fully rational' control over the sets of the many direct (>500) and indirect (1000s) of HIF affected genes is likely to be challenging. ${ }^{[76]}$ As we, and others, have found, epigenetic factors, including histone tail modifications and epigenetic enzymes likely also play important roles in regulating HIF target gene expression. ${ }^{[95-97]}$ However, as yet no other hypoxia/dioxygen sensors apart from the PHDs/FIH have been identified for the HIF system, though other 2OG oxygenases have been shown to have the potential to act in this capacity (e.g. histone demethylases). ${ }^{[98-100]}$

The discovery of the roles of the HIF hydroxylases in signalling, coupled with a desire to carry out basic science to enable prosecution of them and, potentially, other $20 \mathrm{G}$ oxygenases as therapeutic targets, motivated us to increase our efforts to attempt comprehensive assignment of the functions of human 2OG oxygenases.

In one line of investigation, stemming from the 'switch or rheostat' like roles of the PHDs in the HIF system, we, and others, have attempted to identify other substrates for the PHDs as well as to identify related prolyl-hydroxylases involved in signalling. Following the initial assignment of the PHDs as HIF- $\alpha$ hydroxylases, multiple alternative substrates for them have been reported. ${ }^{[101]}$ However, the precise physiologically relevant roles of these proposed prolyl-hydroxylations are unclear and in few, if any, cases have definitive biochemical assignments of the alternative substrates been reported.

\section{New Prolyl Hydroxylases}

Following from our work on prokaryotic proline hydroxylases, ${ }^{[102,103]}$ which we found to be capable of catalysing types of oxidation other than 'simple' mono-hydroxylations, e.g. epoxidation/dihydroxylation, ${ }^{[11]}$ we were interested to investigate if such reactions were also a property of (some) animal 2OG oxygenases. It should be noted that prolyl-residues are often associated with stabilisation of specific protein conformations e.g. they are often present at turns and ( $\mathrm{C}-4$ hydroxylated) prolylresidues stabilise the collagen triple helix fold. ${ }^{[26,104]}$ The presence of prolyl residues at, often exposed, turns may reflect their propensity for hydroxylation, both in proteins and in cyclic peptides produced in secondary metabolism.

One biologically interesting line of investigation has involved studies on PHD homologues in non-animals. The groups of West and Blader have shown that in some early eukaryotes (e.g. Dictyoslelium discoideum and Toxoplasma gondii) PHD homologues catalyse the hydroxylation of Skp1, a subunit of the Skp1/Cullin-1/F-box protein (SCF)-class of E3-ubiquitin ligases, which is involved in transcriptional regulation. ${ }^{[105,106]}$ Prolylhydroxylation of SKP1 enables glycosylation, which is proposed to regulate assembly of an E3-ligase complex. ${ }^{[107]}$ There is some evidence that the PHD homologues in early animals have a role in the hypoxic response, though as yet the link between the 'enzymology' and the hypoxic response at the whole organism level is not as direct as that for the animal PHDs.

Because of our work on microbial biosynthesis, we were interested to investigate the possibility of protein/prolylhydroxylases in prokaryotes. Bioinformatic searches, informed by crystallographic analyses on the PHDs and other $20 \mathrm{O}$ oxygenases, suggested the presence of PHD homologues in some bacteria, including Pseudomonas spp. ${ }^{[108]}$ Proteomic analyses employing mass spectrometry, coupled to peptide screening studies, identified a prolyl-residue in the switch 1 loop of elongation factor-thermally unstable (EF-Tu) as a substrate for a Pseudomonas PHD homologue (PPHD). Analytical studies revealed the selectivity of EF-Tu prolyl-hydroxylation as the same as that of the PHDs (i.e. trans C-4). As yet the biological functions of EF-Tu prolyl hydroxylation have not been clearly identified. EF$\mathrm{Tu}$ is a highly abundant GTPase that plays a central role in translation via catalysing the binding of aminoacyl tRNA complexes to ribosomes. Prolyl-hydroxylation does not ablate the GTPase activity of EF-Tu. There is evidence that PPHD is involved in iron metabolism, though given the role of EF-Tu in translation the effect of its prolyl-hydroxylation could be highly pleiotropic.

Crystallographic analyses on PPHD with and without EF-Tu represent the first example of a $20 \mathrm{G}$ oxygenase in complex with an intact protein-substrate. ${ }^{[108]}$ They reveal that very substantial changes in the (catalytically important) switch 1 loop of EF-Tu occur in order for it to bind productively at the PPHD active site. The conformational changes in the EF-Tu substrate are matched 
by complementary changes in the C-terminal region of PPHD, including in an 'insert/loop' that links two of the strands of the DSBH core fold. Such induced fit is common in $20 \mathrm{O}$ oxygenase catalysis, as revealed by crystallographic and NMR studies (on AlkB and PHD2). ${ }^{[72,109]}$ From an evolutionary perspective, crystallographically informed DNA/protein sequence analysis suggests that the PHDs in animals likely evolved from prokaryotic $2 O G$ oxygenases of the DAOCS subfamily, possibly from PPHD (like) enzymes, ${ }^{[108]}$ via the Skp1 hydroxylation PHD homologues in early animals (see below). ${ }^{[105,106]}$ Evolutionary branch points to give the procollagen type prolyl hydroxylases (which can have substrates other than procollagens) and to give OGFOD1/oxygenase-homologues likely occurred in early eukaryotes. However, given the close similarity of the PHD core fold and PPHD, horizontal gene transfer to give the latter cannot be ruled out. ${ }^{[108]}$

Our structurally informed bioinformatic studies also identified another potential (prolyl) hydroxylase that appeared to be conserved in organisms ranging from yeast to humans. Subsequent work with yeast (Saccharomyces cerevisiae), insect (Drosophila melanogaster with Pablo Wappner), and human cells (with Peter Ratcliffe) identified the putative 2OG oxygenase (OGFOD1 in humans) as acting on the C-3 position of a prolylresidue in the ribosomal small subunit protein in RPS23/uS12. ${ }^{[10-}$ 113] The position at which OGFOD1 catalyses prolyl hydroxylation is at the closest point of contact between any ribosomal protein residue and mRNA, as revealed by biophysical (crystallographic and electron microscopy) analyses on intact ribosomes. Interestingly, the $S$. cerevisiae OGFOD1 homologue, TPA1, apparently catalyses a second hydroxylation, likely at the C-4 position. ${ }^{[12]}$ Crystallographic analyses reveal OGFOD1 (and closely related enzymes ${ }^{[114]}$ as having a dual DSBH containing fold, with the active site present in the $N$-terminal domain, and the other DSBH domain potentially being involved in RPS23 substrate binding (there are no enzyme-substrate complex structures for OGFOD1 reported as yet), or binding to another OGFOD1 partner protein. ${ }^{[113]}$ Given the apparent highly conserved nature of the OGFOD1 reaction and the position of its prolyl hydroxylation at the 'heart' of the protein biosynthesis machinery, its function is of considerable interest. The active sites of the PHDs and OGFOD1 are similar (but by no means identical), and, at least some, of the PHD inhibitors also inhibit OGFOD1. ${ }^{[113]}$ This observation is of interest to medicinal chemistry on the PHDs, especially for long term therapies, such as is the case for treatment of anaemia. Notably, biochemical analysis employing MS, NMR and amino acid analyses revealed OGFOD1 (and both its insect ( $D$. melanogaster) and yeast ( $S$. cerevisiae) OGFOD1 homologues) catalyse C-3 trans prolyl-hydroxylation, contrasting with the regio- and stereoselectivity of PHD and PPHDs catalysis, both of which give the trans $\mathrm{C}-4$ hydroxylated products.

The biological roles of RPS23 hydroxylation in animals are not yet established. OGFOD1 is also reported to have roles in stress responses, though RPS23 does not appear to be as sensitive as HIF- $\alpha$ hydroxylation to changes in dioxygen availability. ${ }^{[110,115]}$ The Espenschade group has reported that the Schizosaccharomyces pombe OGFOD1 homologue, Ofd1, in combination with the nuclear import adaptor, Nro1, regulates the activity of SRE1, the yeast sterol regulatory element binding protein. ${ }^{[116,117]}$ Ofd1 is reported to catalyse dihydroxylation of Rps23 when complexed with Nro1. Hypoxia reduces Ofd1 catalysis, so stabilizing the Ofd1-Rps23-Nro1 complex, and so preventing Ofd1 from binding Sre1, which is then free to promote transcription of genes involved in the hypoxic response. This mechanism echoes that proposed for FIH in terms of competition between HIF- $\alpha$ and ankyrin repeat domain proteins (see below). ${ }^{[118,119]}$ Indeed, such competition between substrates may be a feature of $20 \mathrm{OG}$ oxygenases involved in regulation of gene expression/protein biosynthesis (as previously proposed for kinases ${ }^{[120]}$.

\section{Factor inhibiting HIF - a promiscuous animal hydroxylase}

As described above, work on PHD-related enzymes was of interest in terms of identifying new protein-modifications and (we hope) will help enable the next generation of improved PHD inhibitors. Analogous investigation on FIH-related enzymes were, to date, to prove even more impactful, from both biochemical and medicinal perspectives. Following the identification of HIF- $\alpha$ CAD asparaginyl hydroxylation by Lando et al., ${ }^{[81]}$ we were interested to identify the enzyme catalysing this reaction. We did not observe CAD hydroxylation with the PHDs, hence pursued alternatives. Semenza had reported $\mathrm{FIH}$ as a HIF negatively regulating protein. ${ }^{[79]}$ We were initially uncertain as to whether FIH was the HIF- $\alpha$ CAD hydroxylase because it (apparently) belonged to a different structural subfamily of $20 \mathrm{O}$ oxygenases to the PHDs. However, FIH was subsequently assigned as the missing HIF- $\alpha$ 
CAD asparaginyl hydroxylase on the basis of studies with recombinant proteins and cellular studies. ${ }^{[80,82,83]}$ Crystallographic studies on $\mathrm{FIH}$, the first of a human $2 \mathrm{OG}$ oxygenase, including in complex with the HIF- $\alpha$ CAD, ${ }^{[121]}$ confirmed the assignment of $\mathrm{FIH}$ as belonging to a different $20 \mathrm{O}$ oxygenase subfamily to the PHDs. Together with crystallographic studies on PHD2 ${ }^{[72]}$ those with $\mathrm{FIH}$ have helped enable the development of selective inhibitors of both $\mathrm{FIH}$ and the PHDs. ${ }^{[82,121,122]}$ Notably, unlike the PHDs, which belong to the monomeric IPNS/DAOCS subfamily of $20 \mathrm{G}$ oxygenases, $\mathrm{FIH}$ is dimeric. ${ }^{[82,121,122]}$

The assignment of $\mathrm{FIH}$ as the HIF- $\alpha$ CAD hydroxylase was important from a wider perspective, because FIH had already been assigned as one of the $\mathrm{JmjC}$ proteins, some of which were known to have roles in chromatin biology/transcriptional regulation. ${ }^{[123]}$ Bioinformatics in the light of the assignment of $\mathrm{FIH}$ as a $20 \mathrm{OG}$ oxygenase and aided by crystallographic studies, implied that many, but likely not all, of the JmjC proteins would be $20 \mathrm{O}$ oxygenases. Subsequent work by us and many others has shown this to indeed be case.

As outlined above, there is not yet definitive evidence for non-HIF PHD substrates; work with $\mathrm{FIH}$, however, has yielded 'polaropposite' results. By contrast to the PHDs we (in collaboration with Peter Ratcliffe) have shown FIH not only catalyses HIF-a CAD asparaginyl hydroxylation, but also that of multiple other protein residues. ${ }^{[124-126]}$ Evidence from cellular interaction studies, proteomic mass spectrometry, assays with peptides/isolated protein substrates, and animal work all support the assignment of $\mathrm{FIH}$ as having multiple substrates from the ankyrin repeat domain (ARD) structural family of proteins, which have multiple biological roles. ${ }^{[127,128]}$

The ARD family is characterised by the presence of an $\sim 33$ residue $\beta$-turn $\alpha$-helix $\alpha$-helix fold. ${ }^{[129]}$ The presence of multiple ARDs in proteins is common. ARDs are present in proteins with very different roles, ranging from cellular structure (e.g. ankyrin R) to signalling (e.g. I $\mathrm{KBa}$ and related proteins) and development (Notch system). ${ }^{[124,130,131]}$ However, the effect of ARD hydroxylation on e.g. Notch or IKBa signalling, appears to be small, at least in the reported contexts. ${ }^{[124,130]}$

In work with synthetic 'consensus' ARD proteins and in limited other cases, we have shown $\mathrm{FIH}$-catalysed hydroxylation can thermodynamically stabilize the ARD fold. ${ }^{[132,133]}$ However, it is important to note that the available evidence is that $\mathrm{FIH}$-catalysed ARD hydroxylation rarely appears to be complete (by contrast to PHD enabled HIF degradation and the extensive/efficient procollagen prolyl-4-hydroxylation), and thus it is perhaps unlikely that 'simple' protein fold stabilization is a conserved general role of ARD hydroxylation.

From a biochemical perspective ARD hydroxylation is interesting. FIH can catalyse C-3 hydroxylation not only of asparaginyl-, but also of aspartyl-and histidinyl-residues in ARDs (as shown in cells and in a few cases in animals) (Figure 10B). ${ }^{[134,135]}$ In studies with isolated peptides $\mathrm{FIH}$ can even catalyse hydroxylation of hydrophobic residues such as leucine. ${ }^{[125]} \mathrm{FIH}$ also likely interacts with ARDs which it does not hydroxylate. ${ }^{[136]}$ These observations provide a nice example of unexpected promiscuity in 2OG oxygenase catalysed modifications of a protein substrate.

The first crystal structures of FIH substrate complexes were with HIF- $\alpha$ fragments and suggested that the hydroxylated asparaginyl-residue was precisely located in a manner involving hydrogen bonding of the asparaginyl primary amide side chain. ${ }^{[121]}$ Clearly, this type of interaction is not involved in $\mathrm{FIH}$ catalysed hydroxylation of resides with hydrophobic side chains. ${ }^{[125,126]}$ Factors regulating the efficiency/selectivity of FIHcatalysed ARD hydroxylation in cells include the residue undergoing hydroxylation, the local surrounding sequence, longer range effects, and the stability of the substrate canonical ARD fold. ${ }^{[127,134,135,137,138]}$ One further interesting aspect of $\mathrm{FIH}$ catalysed ARD hydroxylation is that the ARD must unwind from its canonical fold in order to bind productively for catalysis at the FIH active site; the details of this are not presently known. ${ }^{[121,130]}$

As yet no unequivocal evidence for FIH catalysis in a direct, 'switch-like' signalling role outside of the HIF system has been reported. There is evidence for competition between ARDs and HIF- $\alpha$ for FIH in cells. Thus, the multiplicity of ARD substrates for $\mathrm{FIH}$ (including some abundant proteins) compared to HIF- $\alpha$, raises the unanswered question of how sufficient $\mathrm{FIH}$ is available for HIF- $\alpha$ hydroxylation. One possibility is that there is a process targeting HIF- $\alpha$ to $\mathrm{FIH}$, which may relate to the dimeric nature of $\mathrm{FIH} .{ }^{[121]}$ Alternatively, FIH/HIF- $\alpha /$ ARD complexes enabled by the dimeric nature of $\mathrm{FIH}$ could play roles in the hypoxic response. ${ }^{[139]}$ Competition between HIF- $\alpha$ and ARDs for FIH may serve to 'fine 
tune' the hypoxic response. ${ }^{[118]}$ The extent to which (some) ARDs bind to $\mathrm{FIH}$ is hindered by hydroxylation (i.e. the hydroxylated products bind less tightly). Since ARD abundance and lifetime vary in a context-dependent manner, it has been proposed that the overall ARD-hydroxylation state has the potential to regulate the fraction of free $\mathrm{FIH}$ available to catalyse HIF- $\alpha \mathrm{CAD}$ hydroxylation, i.e. this represents a potential mechanism for physiologically observed hypoxic memory effects. ${ }^{[118]}$ Mouse model studies suggest that $\mathrm{FIH}$ is less important in the HIF mediated hypoxic response than the PHDs (at least PHD2). ${ }^{[6-88]}$ A fine tuning role for $\mathrm{FIH}$ is consistent with the relatively mild phenotypes associated with mice in which FIH is deleted. ${ }^{[86-88]}$

Overall, the FIH work exemplifies an ongoing challenge for us and our collaborators, i.e. attempting, and usually failing, to 'directly' connect biochemically-interesting oxygenase-catalysed postoligomerization modifications to proteins and nucleic acids with physiology/disease. Such connections are obvious in some cases e.g. the roles of $20 \mathrm{OG}$ oxygenases in small-molecule/lipid metabolism, but are usually much more challenging in work with oligomers. The roles of the PHDs in the hypoxic response is perhaps an unusually direct connection between an oxygenasecatalysed post-oligomerization modification and physiology - the work on FIH exemplifies the potential complexity of the roles of enzyme catalysis in transcriptional/'epigenetic' regulation.

\section{JmjC proteins and ribosomal oxygenases}

A major activity in our group, and others, over the last 15 years has been to assign biochemical, cellular, and physiologically relevant roles to the JmjC and other human $20 \mathrm{G}$ oxygenases. At the onset of this work we anticipated that other hypoxia/dioxygen sensors with similar 'switch-like' (to a very crude first approximation) signalling roles to those of the PHDs and $\mathrm{FIH}$ would be discovered. However, although some of the JmjC and other human oxygenases have been shown to have the potential to be regulated by dioxygen availability in cells (for example we, and others, have recently shown that members of the KDM4 subfamily of JmjC KDMs have dioxygen $\mathrm{K}_{M}$ values within physiological ranges), ${ }^{[8,100]}$ and some JmjC oxygenases have been found to have roles in the HIF- $\alpha$ mediated hypoxic response, no other (human) $20 \mathrm{O}$ oxygenases have as yet been found to have any pivotal roles in hypoxic sensing. In addition to attempting to define roles for 'orphan' human $20 \mathrm{O}$ oxygenases, we remain interested in identifying non HIF substrates for the PHDs and $\mathrm{FIH}$.

A breakthrough in functional assignment work on JmjC proteins, came with the finding that a large subset of JmjC proteins are histone $N^{\varepsilon}$-methyllysine demethylases (KDMs). Following, the initial pioneering studies by Tsukada et al., and Whetstine et al., $\sim 6$ human families of JmjC KDMs have been identified. ${ }^{[140-143]}$ Although biochemical evidence for $N^{\varepsilon}$-methyllysine histone demethylation had long been known, ${ }^{[144]}$ the identity of the KDMs had been elusive for decades and many believed histone lysine methylation was irreversible. In fact, the JmjC KDMs were not the first family of KDMs discovered, with the smaller set of flavindependent KDM1 enzymes being the first to be identified. ${ }^{[145,146]}$

JmjC KDM catalysis proceeds via initial $N^{\varepsilon}$-methyl group hydroxylation, followed by fragmentation of the resultant hemiaminal to give the demethylated product and formaldehyde (Figure 11). ${ }^{[147]}$ In the case of JmjC KDMs, to date, this hemiaminal species has proven too short-lived to observe. In the case of the mechanistically related DNA demethylase, AlkB (discussed below), ${ }^{[148,149]}$ a crystal structure of the enzyme bound to this reaction intermediate has been solved, ${ }^{[150]}$ and for the human nucleic acid oxygenase, FTO, the formation of stable hemiaminal products have been observed. ${ }^{[151,152]}$ In addition, work on lysine analogues in our group, see below, has led to observation of a stable $\beta$-hydroxylated alkyl group, further confirming the proposed reaction mechanism. ${ }^{[153]}$ Unlike the KDM1s, which for mechanistic reasons can only act on the monoand dimethylated states, the JmjC KDMs can act on all lysine $N^{\varepsilon}$ methylation states (including $\mathrm{KMe}_{3}$ ). ${ }^{[147]}$ Other $\mathrm{JmjC}$ proteins with a 2OG oxygenase fold include apparent pseudo-enzymes (unusual activities for these cannot be excluded), likely evolved from catalytically active JmjC KDMs (e.g. JARID2) and enzymes that catalyse the productions of indefinitely stable alcohol

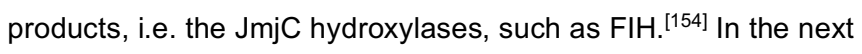
sections, we summarise aspects of work on the JmjC enzymes, focussing on substrate and product selectivity. 


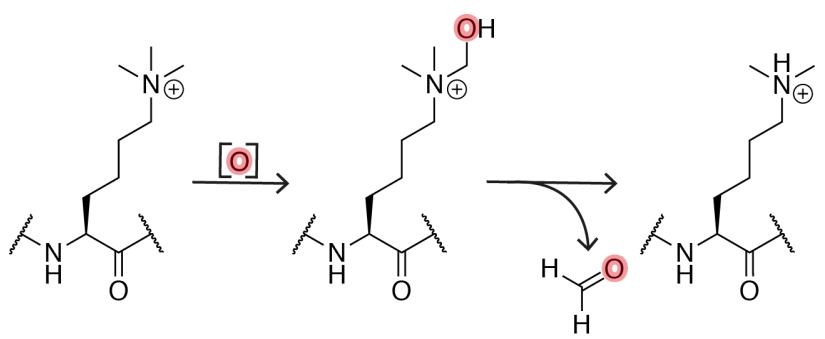

Figure 11. Mechanism of lysine demethylation as catalysed by the $\mathrm{JmjC}$ histone lysine demethylases. $[\mathrm{O}]=2 \mathrm{OG}$ oxygenase catalysed step coupled to conversion of $2 \mathrm{OG}$ and dioxygen into succinate and carbon dioxide.

The identification of $N^{\varepsilon}$-methyllysine demethylases was of importance in the fields of genetics and biology because of the key role of histone lysyl-residue methylation in regulating transcription. Overall, basic residues (Lys, Arg, His) appear to be often modified by $20 \mathrm{O}$ oxygenases (and other enzymes) with Lys being particularly prone to modification. In addition to methylation/demethylation, lysyl-residues are modified by C-3, ${ }^{[155]}$ $\mathrm{C}-4,{ }^{[156]}$ and $\mathrm{C}-5^{[1,157]}$ hydroxylation as well as by acetylation, ubiquitination, and formylation. ${ }^{[158,159]}$ The reasons for the propensity of these residues to be modified may reflect their frequent location on the exterior of proteins, the presence of methylene groups for modification, and their roles in biologically important processes.

\section{Ribosomal oxygenases}

In addition to their roles in transcriptional regulation, 2OG oxygenases also act at the translational level. As related above, OGFOD1 catalyses ribosomal protein prolyl-hydroxylation, ${ }^{[110-112]}$ and a possible ancestor of the PHDs is also involved in modification of the translation machinery, i.e. PPHD catalysed hydroxylation of EF-Tu. ${ }^{[108]} \mathrm{JmjC}$ hydroxylases that modify ribosomes and associated protein have also been identified. In Escherichia coli and other bacteria, YcfD catalyses C-3 hydroxylation of an arginyl-residue in the $50 \mathrm{~S}$ ribosomal protein L16 (rpl16). ${ }^{[160]}$ In humans, and likely other animals, YcfD homologues (MINA53 and NO66) also catalyse C-3 hydroxylations of ribosomal proteins, but in this case of histidylresidues (in rpl27a and rpl8, respectively). ${ }^{[161]}$ The overall folds of these ribosomal oxygenase proteins are highly conserved from bacteria to humans, including with the presence of a characteristic winged helix domain, which may be involved in nucleic acid interactions. A YcfD homologue is present in the thermophilic organism, Rhodothermus marinus, and manifests appropriate temperature dependent kinetic properties / stability. ${ }^{[162]}$

A<smiles>CCC(C)NC(CCC(O)C[NH3+])C(=O)C(CC)NC(C)C</smiles>

B

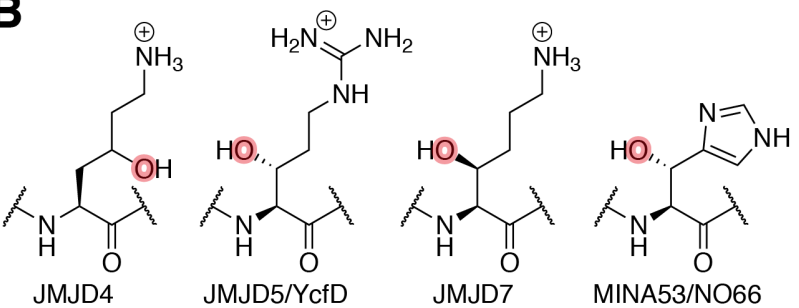

C<smiles>[R]n1cnc2c(=O)n3c(CC[C@H](N)C(=O)O)c(C)nc3n(C)c21</smiles>

7-(a-amino-a-carboxypropyl)wyosine<smiles>Cc1nc2c(n1CC(O)C(N)C(=O)O)N(C)c1c(ncn1P)C(=O)N2C</smiles>
$\downarrow$ TYW4<smiles>[R]OC(=O)N[C@H](Cc1c(C)nc2n(C)c3[nH]cnc3c(=O)n12)C(=O)OC</smiles>

hydroxywybutosine

Figure 12. Hydroxylation of lysyl-, histidyl- and arginyl-residues catalysed by human $20 \mathrm{O}$ oxygenases. (A) Hydroxylation of lysine as catalysed by JMJD6. (B) Hydroxylated products produced by the indicated JmjC hydroxylases. (C) Hydroxylation of the modified nucleoside, wybutosine by TYW5. [O] = 2OG oxygenase catalysed step coupled to conversion of $20 \mathrm{G}$ and dioxygen into succinate and carbon dioxide.

The precise biochemical/cellular roles of these hydroxylations are unclear, but there is evidence ribosome hydroxylation is linked to cell growth. We have also assigned JMJD4, JMJD5, JMJD6, and JMJD7 as $20 \mathrm{G}$ dependent protein hydroxylases (Figure 12). ${ }^{[155-}$ 157,163] JMJD4, JMJD6 and JMJD7 are all lysyl-hydroxylases, but with different regio- and stereo-selectivities. JMJD6 has been assigned by others as an $N$-methylarginyl histone demethylase, ${ }^{[164,165]}$ but our evidence (as supported by some others) is that it is a lysyl C-5 hydroxylase acting on both RNA splicing regulatory proteins and histone tails (Figure 13A). ${ }^{[157,166-}$ 170] JMJD5 is interesting because, like bacterial YcfD, it is an 
arginyl C-3 hydroxylase, catalysing production of the $(3 R)$ hydroxylated product (Figure 12B). ${ }^{[163]}$ As for FIH catalysed ARDhydroxylation, none of the other JmjC hydroxylase catalysed reactions have as yet been shown to have 'switch like' effects on the roles/selectivities of their substrates.

Another JmjC hydroxylase, TYW5, is of particular note from a selectivity perspective. To date, other JmjC $20 \mathrm{G}$ oxygenases have been found to act on proteins, but TYW5 catalyses nucleic acid modification, though it is clearly not a member of the AlkB structural subfamily of nucleic acid modifying 2OG oxygenases. ${ }^{[171-173]}$ TYW5 catalyses tRNA hydroxylation in the wybutosine biosynthesis pathway and is a nice example of flexibility in evolution of $20 \mathrm{O}$ oxygenases to accept new substrate types (Figure 12C).

\section{Histone demethylases and nucleic acid oxygenases}

Most, if not all, of the JmjC KDMs are multidomain proteins, with the non-catalytic domains often playing roles in targeting the JmjC domain to specific histone modifications. ${ }^{[154]}$ It is, however, notable that non-covalent reactions including histone tail binding proteins/enzymes are important, hence the JmjC KDMs should not be regarded as simple 'mono-functional' enzymes as, e.g. $2 O G$ oxygenases involved in small molecule biosynthesis often appear to be. Indeed in a number of cases catalytically inactive protein variants have been demonstrated to rescue some phenotypes resulting from knockout of the wildtype JmjC KDMs. ${ }^{[174-176]}$ With these caveats, it is likely many JmjC KDMs have important roles in transcriptional regulation in eukaryotes. ${ }^{[177]} N^{\varepsilon}$-Methylation of lysyl-residues in histone tails, particularly that of histone $\mathrm{H} 3$, plays key roles in both promoting and inhibiting transcription. ${ }^{[178]}$ Hence, proteins that modulate histone methylation states and the activity of specific histone marks are of considerable medical interest.

Possibly, the clearest example of targeting of JmjC KDM activity via a non-catalytic domain is KDM7B (PHF8), wherein a plant homeobox domain adjacent to the JmjC KDM domain binds histone $\mathrm{H}_{3} \mathrm{~K}_{4} \mathrm{Me}_{3}$ in order to 'direct' JmjC KDM activity to the $\mathrm{H}_{3} \mathrm{~K}_{\mathrm{MMe}}$ residue. ${ }^{[179-183]}$ Modification to the loop linking the plant homeobox and JmjC KDM domains, as in KDM7A (KIAA1718), reverses this effect, with the $\mathrm{H}_{3 K 4 M e}$ inhibiting KDM7A catalysed demethylation at $\mathrm{H} 3 \mathrm{~K} 9 \mathrm{Me}_{2} \cdot{ }^{[179]}$

A second example of selectivity arose from our work on the KDM4 subfamily of JmjC KDMs, in collaboration with Udo Oppermann of the Structural Genomics Consortium. The KDM4 subfamily catalyses demethylation of all three $N^{\varepsilon}$-methylation states of H3K9Men (human KDM4A-E) and H3K36Men (KDM4A-C, but not KDM4D-E), as well as potentially at other positions. ${ }^{[184-186]}$ Crystallographic analyses on KDM4A substrate complexes have provided insights into how the enzyme accommodates all $\mathrm{KMe}_{\mathrm{n}}$ methylation states as well as both $\mathrm{H}_{3} \mathrm{~K} 9 \mathrm{Me}_{\mathrm{n}}$ and $\mathrm{H} 3 \mathrm{~K} 36 \mathrm{me}_{\mathrm{n}}$ substrates. ${ }^{[185,187]}$ Structurally informed mutagenesis studies imply multiple substitutions enable the differential selectivities of KDM4A-C (which accepts $\mathrm{H} 3 \mathrm{~K} 9$ and H3K36 methylation) and KDM4D-E (which accepts H3K9 methylation, but not H3K36 methylation) and have provided insight into the evolution of substrate selectivity in the $\mathrm{JmjC}$ KDMs. ${ }^{[188]}$

A<smiles>CCC(CC)NC(CCCCN(C)C(C)CO)C(=O)C(CC)NC(C)C</smiles>

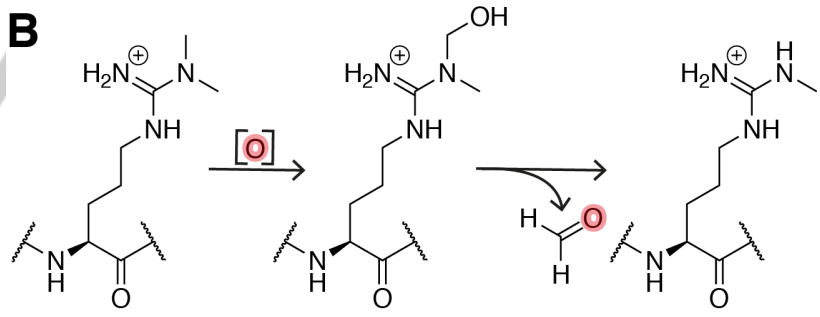

Figure 13. Arginine demethylation is catalysed by a subset of JmjC KDMs. (A) Substrate analogue studies leading to formation of stable alcohol products via KDM4E catalysed oxidation of $N^{\varepsilon}$-methyl,isopropyllysine. Note the structural similarity between $N^{\varepsilon}$-methyl,isopropyllysine and asymmetric dimethylarginine. (B) Arginine demethylation is catalysed by a subset of JmjC KDMs. [O] = 2OG oxygenase catalysed step coupled to conversion of $20 \mathrm{G}$ and dioxygen into succinate and carbon dioxide.

Inspired by the success of substrate analogue studies on microbial $20 \mathrm{OG}$ oxygenases we have been exploring the scope of JmjC KDM catalysis employing substrate analogues. These studies have demonstrated that the active sites of these enzymes are extremely plastic, allowing a-hydroxylation and subsequent 
removal of a wide-range of alkyl substituents in addition to methyl groups. ${ }^{[153,189]}$ They have revealed clear differences in the capacity of different JmjC KDMs to catalyse oxidation of substrate analogues, likely reflecting differences in both the size and electronics of the active sites. For most, but not necessarily all, JmjC KDMs, a positively charged substrate is preferred. The results also revealed that some JmjC KDMs will catalyse hydroxylations to give stable alcohol products (Figure 13A). ${ }^{[153]}$ In addition to its mechanistic relevance, this work led us to explore the propensity of JmjC KDMs to catalyse hydroxylation and subsequent demethylation of dimethylated arginyl-residues, ${ }^{[190]}$ of which the asymmetric form is roughly isosteric with $N^{\varepsilon}$ methyl,isopropyllysine.

Interestingly, we have found that some, but not all, JmjC KDMs have $\mathrm{N}$-methylarginine demethylase (RDM) activity, including with both symmetric and asymmetric forms of dimethylated arginine residues (Figure 13B). ${ }^{[190]}$ As yet we have not been able to robustly demonstrate RDM activity in cells, and hence have reported our work with isolated enzymes, in the hope it may help others in biological work involving JmjC oxygenases. ${ }^{[191]}$ Our inability to definitively demonstrate RDM activity in cells likely reflects a lack of suitable antibodies (including for unmodified forms of the residues under study), the complexities of histone tail modifications, and difficulties in assaying for the removal of a modification. Recently, however, Li et al. have reported a role for cellular demethylation of $\mathrm{H} 4 \mathrm{R} 3 \mathrm{me} 2 \mathrm{a}$ by $\mathrm{KDM} 3 \mathrm{~B}$ in haematopoiesis. ${ }^{[191]}$

\section{Nucleic acid oxygenases}

Although this article focusses on 2OG oxygenases catalysing reactions on proteins/peptides, given the focus of the issue on epigenetics it is relevant to touch on work concerning animal nucleic acid oxygenases. In early studies on mechanisms of DNA damage repair, the bacterial $20 \mathrm{G}$ oxygenase, AlkB, was reported to catalyse the demethylation of nucleic acids methylated by methylating agents. Like JmjC KDMs, AlkB catalysis proceeds via initial $\mathrm{N}$-methyl group hydroxylation to give a hemi-aminal type intermediate, which fragments to give formaldehyde and the 'repaired' demethylated nucleic acid (Figure 14A). ${ }^{[148,149]}$

$$
\text { (O)] }
$$

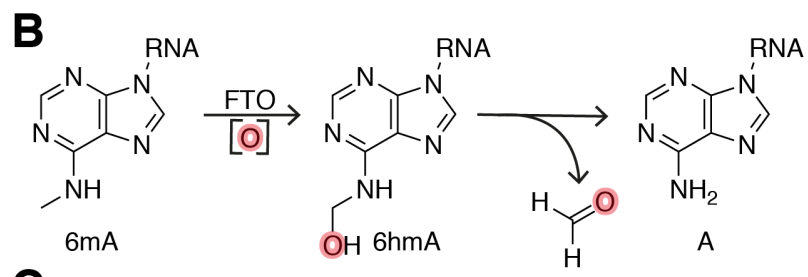

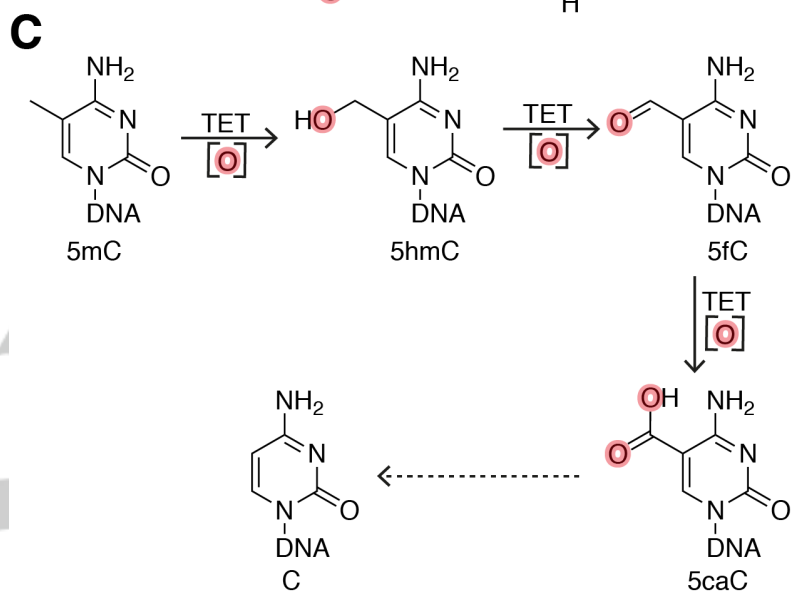

Figure 14. $20 \mathrm{G}$ oxygenase-catalysed nucleic acid reactions. (A) Demethylation of 3-methylcytosine by AlkB. (B) Demethylation of 6-methyladenosine as catalysed by FTO. (C) Oxidation reactions catalysed by the TET oxygenases. $[O]=2 O G$ oxygenase catalysed step coupled to conversion of $20 \mathrm{G}$ and dioxygen into succinate and carbon dioxide.

Homologues of AlkB (ABHs) are very widely distributed (though, like other 206 oxygenases, appear absent in Archaea). In humans, the known $20 \mathrm{O}$ oxygenases acting on nucleic acids comprise $\sim 8$ human AlkB homologues: $\mathrm{ABH} 1-8,{ }^{[192,193]}$ the fatty mass and obesity associated protein (FTO) ${ }^{[194]}$ and the Teneleven translocation methylcytosine dioxygenases (TET enzymes: human TET1-3). ${ }^{[195,196]}$ Like AlkB in bacteria, ABH1/2/3 are probably involved in DNA damage repair. ${ }^{[193,197]}$ Following the report of links between obesity/body mass and mutations to the gene for FTO, we assigned FTO as a nucleic acid oxygenase. ${ }^{[198]}$ Subsequent work by the He group has shown FTO and ABH5 preferentially accept $\mathrm{N}$-methylated RNA, catalysing demethylation of bases, including, for FTO, single-stranded RNA containing 3-methyluracil as well as single-stranded DNA containing 3-methylthymine, and, for $\mathrm{ABH} 5,6$-methyladenosine (Figure 14B). ${ }^{[199-201]}$ RNA $N$-methylation is linked to biological 
processes including circadian rhythm and stress responses. ${ }^{[202]}$ Perhaps of most current interest from the epigenetics perspective are the TET oxygenases, which catalyse sequential oxidation of 5 -methylcytosine to give 5-hydroxymethyl- $(5 \mathrm{hmC}),{ }^{\text {,203] }} 5$-formyl$(5 \mathrm{fC}),{ }^{[204,205]}$ then, 5-carboxycytosine (5caC) (Figure 14C). ${ }^{[206,207]}$ TET catalysed modification of 5-methylcytosine has been associated with either direct or indirect 5-methylcytosine demethylation (via excision by thymine DNA glycosylase and subsequent base excision repair). ${ }^{[208,209]}$ Given the importance of 5 -methylcytosine in epigenetic regulation, the discovery of the TET reaction was of substantial interest; more recently it has become apparent that $5 \mathrm{hmC}, 5 \mathrm{fC}$ and $5 \mathrm{caC}$ may also have signalling or regulatory functions in their own right. ${ }^{[208,210]}$ As has been found for JmjC KDMs, the TET proteins are frequently mutated in cancers and as such a better understanding of their full biological roles may be important for the treatment of human diseases, including cancer and developmental disorders. ${ }^{[211]}$

\section{A note on methods}

In work on the functional assignment of 2OG oxygenases catalysing protein modifications, we have normally selected enzymes for study on the basis of prior 'biological literature', potentially interesting chemical features and/or on the basis of strong evolutionary conservation. In the case of $Y c f D$, we were particularly interested to investigate if $20 \mathrm{O}$ dependent protein hydroxylases are present in bacteria. ${ }^{[160]}$ After target selection, we typically then carry out searches for potential substrates in cells employing tagged enzyme and non-reactive $20 \mathrm{O}$ mimicking inhibitors, usually $\mathrm{N}$-oxalylglycine, aiming to co-purify (potential) substrates. Subsequent cellular work involves validating potential enzyme-substrate interactions, initially using tagged/'overproduced' recombinant forms of the substrates. Validation of the interactions is then carried out at endogenous levels, using available antibodies. Proteomic mass spectrometry (MS) can be used to make provisional assignments of post-translational modifications (e.g. hydroxylation for +16 Da). Note MS assignments of demethylation are more difficult because initial methylation is required first. Such assignments are particularly challenging for protein regions that are heavily modified and rich in charged residues (e.g. the histone $\mathrm{H} 3 \mathrm{~N}$-terminal tail). Along with the cellular work, we carry out studies with isolated recombinant enzymes and substrates and, where useful, carry out co-expression studies in E. coli. e.g. when a potential substrate cannot be isolated in an appropriately folded form. MSbased assignments with recombinant protein are supported by studies with peptide fragments (where possible). In cases where recombinant proteins cannot be produced we have used assays with overlapping ('tiled') peptides to search for substrates. ${ }^{[160]}$

In both the cellular and isolated protein work, we employ controls using inhibitors, e.g. N-oxalylglycine/Fe"l chelators, and catalytically inactive oxygenase variants (usually substituted at

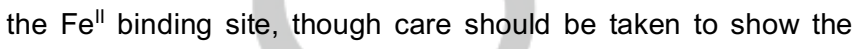
variant is actually inactive/doesn't bind Fe"/2OG, as some $2 \mathrm{OG}$ oxygenases (e.g. FIH) can be active with only two Fell ligands) ${ }^{[212]}$. Cellular controls additionally employ mutation/depletion/ablation of the enzymes/substrates under study, using techniques such as sh/siRNA or CRISPR. Ultimately, animal/whole organism studies can be carried out where appropriate.

From a chemical perspective, we believe it is important to validate proteomic analyses by NMR and amino acids analysis (following acidic hydrolysis of substrates) employing commercially available or synthetic standards. In our view these methods should be more widely used, especially the use of 'classical' amino acid analyses to validate proteomic MS results. The peptide work can also supply useful standards for use in proteomic MS work. These rigorous analyses are important, not only to assign the precise nature of the modifications (including their regio- and stereoselectivity), but also because of the possibility of artefacts, due to non-enzymatic oxidation of, e.g. methionine, tyrosine, or tryptophan residues.

We also attempt to predict biochemical function based on structural information, though we have found this difficult for unprecedented reactions. It should also be noted that the order of our studies sometimes reflects the interests of the particular researchers involved. Further there are often challenges with the aforedescribed methods with which we have developed expertise over time. Hard work coupled with luck can also be useful. Indeed, the assignment of YcfD as an arginyl-hydroxylase came initially by screening of available peptides - the peptide sequence of the initial 'hit' was from Pseudomonas spp. ${ }^{[160]}$ This hit led us to reevaluate proteomic MS data from $E$. coli, leading to the assignment of $L 16$ as a YcfD substrate. ${ }^{[160]}$ 


\section{3. $20 \mathrm{O}$ oxygenase inhibitors}

Reviewing progress on $20 \mathrm{G}$ oxygenase inhibition is beyond the scope of this article. From a historical perspective, it is important to state that globally important agrochemicals target 2OG oxygenases and the mechanistically related, but structurally distinct, para-hydroxy phenyl pyruvate dioxygenase. ${ }^{[213]} \mathrm{PHD}$ inhibitors, in part inspired by the agrochemical work along with attempts to inhibit the procollagen prolyl hydroxylases for treatment of antifibrotic diseases, are presently in late stage clinical trials for the treatment of anaemia resulting from chronic kidney disease (Figure 15A). ${ }^{[14,215]} \mathrm{JmjC}$ KDM inhibitors are also being developed for cancer treatment. ${ }^{[216]}$ In the latter regard it is interesting that the plant growth regulator, daminozide, is a selective inhibitor of the KDM2/7 subfamilies of JmjC KDMs (Figure 15B). ${ }^{[217]}$ All of the aforementioned compounds likely inhibit via active site binding involving $\mathrm{Fe}^{\| \prime}$ chelation. They are also likely incompletely selective (though this is not necessarily incompatible with their agrochemical/medicinal applications). There is a need for new types of $20 \mathrm{O}$ oxygenase inhibitor, including for use in functional assignment studies on complex multidomain 2OG oxygenase-containing proteins. Insights from peptide substrate studies inspired us to link short histone fragments with $20 \mathrm{G}$ analogues, producing JmjC KDMs that thus compete with both substrate and co-substrate binding, allowing for subfamily selective inhibition (Figure $15 \mathrm{C}$, left). ${ }^{[218]}$ More recent work with cyclic peptides (and more classical small molecules) targeting the JmjC KDMs has shown that high selectivity can be achieved via substrate competing inhibitors alone (Figure 15C, right). ${ }^{[219]}$ Meldonium represents a 'left-field' method of inhibiting a $20 \mathrm{OG}$ oxygenase (BBOX), but it was not discovered by studies on an isolated enzyme (Figure 9C). ${ }^{[220,221]}$ Inspired by the mode of action of aspirin, in modulating but not ablating, cyclooxygenase activity, we are interested in helping develop compounds that act analogously on $20 \mathrm{G}$ oxygenases, especially those with roles in sensing such as the PHDs.

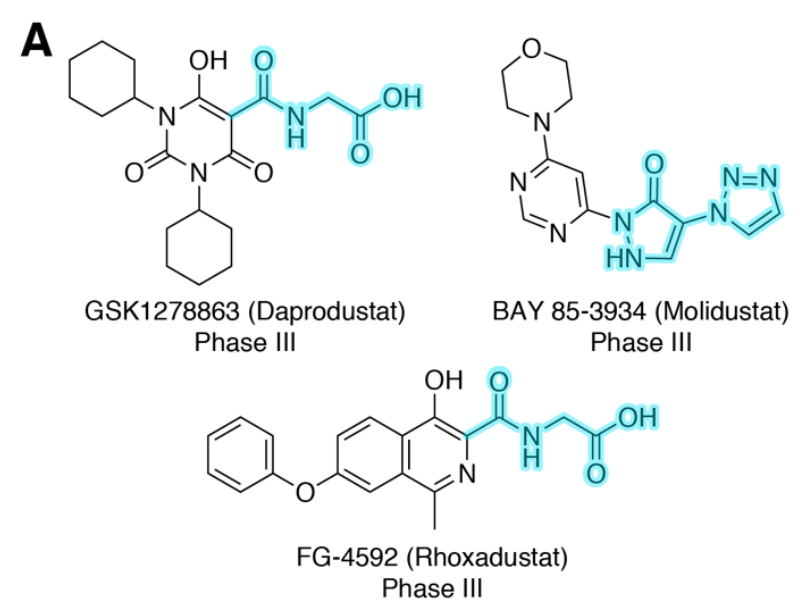

B<smiles>CN(C)NC(=O)CCC(=O)O</smiles>

C

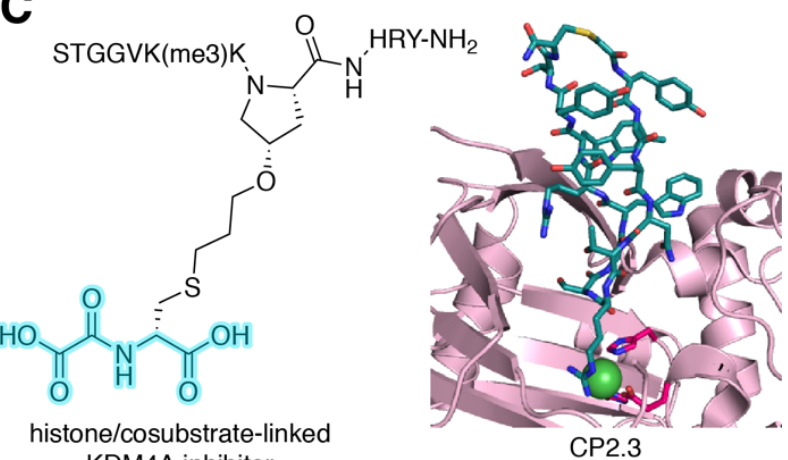
KDM4A inhibitor

Figure 15. $20 \mathrm{G}$ oxygenase inhibitors. (A) Representative PHD inhibitors currently in clinical trials. (B) The plant growth inhibitor, daminozide, is a selective inhibitor of the KDM2/7 subfamilies of JmjC KDMs. (C) Substrate competitive JmjC KDM inhibitors. Right-hand side shows view from a crystal structure of the cyclic peptide inhibitor CP2 bound to KDM4A (5LY1). ${ }^{[19]}$ Elements highlighted in cyan are structurally related to the co-substrate, 2OG.

\section{Conclusions and Future Avenues}

Our work aims to combine interesting organic chemistry with basic biology, ultimately aiming to be useful from a medicinal/societal perspective. This personal account has aimed to give an overview of the work of our group (and its collaborators) on functional assignment work on $20 \mathrm{O}$ oxygenases, describing how the work on human enzymes has its origins in work motivated by the unique mechanisms involved in penicillin and cephalosporin antibiotic biosynthesis. 
As yet, the identified reactions catalysed by human 2OG oxygenases are limited to hydroxylation and hydroxylationmediated demethylation. The nature of the hemi-aminal intermediates involved in demethylation reactions does, however, open up the possibility of Mannich-type reactions being involved in chromatin chemistry, potentially leading to ring structures. ${ }^{[222]}$ Aside from the work with microbial $20 \mathrm{O}$ oxygenase, the potential for such chemistry is supported by work on the mechanism and action of Meldonium, ${ }^{[55]}$ and evidence for the formation of relatively stable hemi-aminal species in catalysis by some demethylases acting on $\mathrm{N}$-methylated nucleic acids. ${ }^{[151,152]}$

We will continue to work to define the function of $20 \mathrm{O}$ oxygenases, including, in animals, those with atypical 'active sites', such as PHF2, Hairless, and JARID2, some of which may catalyse new types of reaction. One line of future investigation for our group will be to explore the roles of animal $20 \mathrm{O}$ oxygenases in ring forming reactions, hoping to find a penicillin-type structure in human biology.

\section{Acknowledgements}

We thank the Wellcome Trust, Cancer Research UK, the Biotechnological and Biological Research Council, the Medical Research Council, the National Institute of Health and companies for funding our basic science work on $20 \mathrm{G}$ oxygenases. LJW has received funding from the European Union's Horizon 2020 research and innovation programme under the Marie Skłodowska-Curie grant agreement No 657292. Many thanks also to the dedicated coworkers who have contributed to our work as well as the other groups who have contributed to the field of functional assignment of $20 \mathrm{G}$ oxygenases. By its nature as a Personal Account, this review is focussed, with a selective reference list. We would like to acknowledge the many scientists whose excellent work is outside the scope of our manuscript.

Keywords: Epigenetics, 2-oxoglutarate and ferrous iron oxygenases, protein hydroxylation, histone demethylases, hypoxia sensing, JmjC KDM, transcription, penicillin biosynthesis.

[1] J. Myllyharju, in 2-Oxoglutarate-Dependent Oxygenases, The Royal Society Of Chemistry, 2015, pp. 149-168.

[2] H. D. Dakin, J. Biol. Chem. 1906, 1, 171-6.

[3] O. Hayaishi, M. Katagiri, S. Rothberg, J. Am. Chem. Soc. 1955, 77, 5450-5451.
[4] H. R. V Arnstein, D. Morris, Biochem. J. 1960, 76, 357-361.

[5] P. A. Fawcett, J. J. Usher, J. A. Huddleston, R. C. Bleaney, J. J. Nisbet, E. P. Abraham, Biochem. J. 1976, 157, 651660.

[6] P. J. Rutledge, in 2-Oxoglutarate-Dependent Oxygenases, The Royal Society Of Chemistry, 2015, pp. 414-424.

[7] R. B. Hamed, J. R. Gomez-Castellanos, L. Henry, C. Ducho, M. A. McDonough, C. J. Schofield, Nat Prod Rep 2013, 30, 21-107.

[8] I. Andersson, K. Valegard, in 2-Oxoglutarate-Dependent Oxygenases, The Royal Society Of Chemistry, 2015, pp. 385-400.

[9] P. L. Roach, I. J. Clifton, V. Fulop, K. Harlos, G. J. Barton, J. Hajdu, I. Andersson, C. J. Schofield, J. E. Baldwin, Nature 1995, 375, 700-704.

[10] W. S. Aik, R. Chowdhury, I. J. Clifton, R. J. Hopkinson, T. Leissing, M. A. McDonough, R. Nowak, C. J. Schofield, L. $\mathrm{J}$. Walport, in 2-Oxoglutarate-Dependent Oxygenases, 2015, pp. 59-94.

[11] R. P. Hausinger, in 2-Oxog/utarate-Dependent Oxygenases, The Royal Society Of Chemistry, 2015, pp. 158.

[12] S. Martinez, R. P. Hausinger, J. Biol. Chem. 2015, 290 20702-20711.

[13] H. M. Hanauske-Abel, V. Günzler, J. Theor. Biol. 1982, 94, 421-455.

[14] J. M. Bollinger Jr., W. Chang, M. L. Matthews, R. J. Martinie, A. K. Boal, C. Krebs, in 2-Oxoglutarate-Dependent Oxygenases, The Royal Society Of Chemistry, 2015, pp. 95-122.

[15] W. Aik, M. A. McDonough, A. Thalhammer, R. Chowdhury, C. J. Schofield, Curr. Opin. Struct. Biol. 2012, 22, 691-700.

[16] I. J. Clifton, M. A. McDonough, D. Ehrismann, N. J. Kershaw, N. Granatino, C. J. Schofield, J. Inorg. Biochem. 2006, 100, 644-669.

[17] A. J. Mitchell, N. P. Dunham, R. J. Martinie, J. A. Bergman, C. J. Pollock, K. Hu, B. D. Allen, W. Chang, A. Silakov, J. M. Bollinger, et al., J. Am. Chem. Soc. 2017, 139, 1383013836.

[18] E. Tamanaha, B. Zhang, Y. Guo, W. Chang, E. W. Barr, G. Xing, J. St. Clair, S. Ye, F. Neese, J. M. Bollinger, et al., J. Am. Chem. Soc. 2016, 138, 8862-8874.

[19] C. P. Pang, B. Chakravarti, R. M. Adlington, H. H. Ting, R. L. White, G. S. Jayatilake, J. E. Baldwin, E. P. Abraham, Biochem. J. 1984, 222, 789 LP-795.

[20] S. Martinez, R. P. Hausinger, Biochemistry 2016, 55, 59895999.

[21] Z. Zhang, T. J. Smart, H. Choi, F. Hardy, C. T. Lohans, M. I. Abboud, M. S. W. Richardson, R. S. Paton, M. A. McDonough, C. J. Schofield, Proc. Natl. Acad. Sci. 2017, 114, 4667 LP-4672.

[22] A. J. Simaan, M. Reglier, in 2-Oxoglutarate-Dependent Oxygenases, The Royal Society Of Chemistry, 2015, pp. 425-437.

[23] Z. Zhang, J.-S. Ren, I. J. Clifton, C. J. Schofield, Chem Biol. 2018, 11, 1383-1394.

[24] Y. Charng, S.-J. Chou, W.-T. Jiaang, S.-T. Chen, S. F. Yang, Arch. Biochem. Biophys. 2001, 385, 179-185.

[25] M. Dubois, L. Van den Broeck, D. Inzé, Trends Plant Sci. 2018, 23, 311-323.

[26] J. Myllyharju, Matrix Biol 2003, 22, 15-24.

[27] S. W. Elson, K. H. Baggaley, J. Gillett, S. Holland, N. H. Nicholson, J. T. Sime, S. R. Woroniecki, J. Chem. Soc., Chem. Commun. 1987, 1739-1740.

[28] J. E. Baldwin, R. M. Adlington, J. S. Bryans, A. O. Bringhen, J. B. Coates, N. P. Crouch, M. D. Lloyd, C. J. Schofield, S. W. Elson, K. H. Baggaley, et al., Tetrahedron 1991, 47, 4089-4100.

[29] S. P. Salowe, E. N. Marsh, C. A. Townsend, Biochemistry 1990, 29, 6499-6508. 
[30] J. E. Baldwin, R. M. Adlington, J. S. Bryans, A. O. Bringhen, J. B. Coates, N. P. Crouch, M. D. Lloyd, C. J. Schofield, S. W. Elson, K. H. Baggaley, et al., J. Chem. Soc., Chem. Commun. 1990, 617-619.

[31] S. P. Salowe, W. J. Krol, D. Iwata-Reuyl, C. A. Townsend, Biochemistry 1991, 30, 2281-2292.

[32] J. E. Baldwin, K.-C. Goh, C. J. Schofield, J. Antibiot. (Tokyo). 1992, 45, 1378-81.

[33] K. H. Baggaley, A. G. Brown, C. J. Schofield, Nat. Prod. Rep. 1997, 14, 309-333.

[34] C. A. Townsend, Curr. Opin. Chem. Biol. 2016, 35, 97-108.

[35] Z. Zhang, J. Ren, K. Harlos, C. H. McKinnon, I. J. Clifton, C. J. Schofield, FEBS Lett 2002, 517, 7-12.

[36] M. A. McDonough, K. L. Kavanagh, D. Butler, T. Searls, U. Oppermann, C. J. Schofield, J. Biol. Chem. 2005, 280, 41101-41110.

[37] N. J. Kershaw, M. E. Caines, M. C. Sleeman, C. J. Schofield, Chem Commun 2005, 4251-4263.

[38] L. A. McNeill, T. J. N. Brown, S. Malkit, I. J. Clifton, N. I. Burzlaff, T. D. W. Claridge, R. M. Adlington, J. E. Baldwin, P. J. Rutledge, C. J. Schofield, Chem. Eur. J. 2017, 23, 12815-12824.

[39] J. E. Baldwin, M. Bradley, Chem. Rev. 1990, 90, 10791088.

[40] J. M. Elkins, M. J. Ryle, I. J. Clifton, J. C. Dunning Hotopp, J. S. Lloyd, N. I. Burzlaff, J. E. Baldwin, R. P. Hausinger, P. L. Roach, Biochemistry 2002, 41, 5185-5192.

[41] K. Valegård, A. C. van Scheltinga, M. D. Lloyd, T. Hara, S. Ramaswamy, A. Perrakis, A. Thompson, H. J. Lee, J. E. Baldwin, C. J. Schofield, et al., Nature 1998, 394, 805-9.

[42] N. I. Burzlaff, P. J. Rutledge, I. J. Clifton, C. M. Hensgens, M. Pickford, R. M. Adlington, P. L. Roach, J. E. Baldwin, Nature 1999, 401, 721-724.

[43] Z. Zhang, J. Ren, D. K. Stammers, J. E. Baldwin, K. Harlos, C. J. Schofield, Nat. Struct. Biol. 2000, 7, 127-33.

[44] R. J. A. Wanders, S. Ferdinandusse, M. S. Ebberink, H. R. Waterham, in 2-Oxoglutarate-Dependent Oxygenases, The Royal Society Of Chemistry, 2015, pp. 338-349.

[45] A. S. Wierzbicki, M. D. Lloyd, C. J. Schofield, M. D. Feher G. F. Brian, J. Neurochem. 2002, 80, 727-735. M. Mukherji, N. J. Kershaw, C. J. Schofield, A. S. Wierzbicki, M. D. Lloyd, Chem. Biol. 2018, 9, 597-605.

[47] M. Mukherji, N. J. Kershaw, C. H. MacKinnon, I. J. Clifton, A. S. Wierzbicki, C. J. Schofield, M. D. Lloyd, Chem. Commun. 2001, 972-973.

[48] G. A. Jansen, H. R. Waterham, R. J. A. Wanders, Hum. Mutat. 2004, 23, 209-218.

[49] F. M. Vaz, N. van Vlies, in 2-Oxoglutarate-Dependent Oxygenases, The Royal Society Of Chemistry, 2015, pp. 324-337.

[50] R. K. Leśniak, S. Markolovic, K. Tars, C. J. Schofield, Chem. Commun. 2017, 53, 440-442.

[51] I. K. H. Leung, T. J. Krojer, G. T. Kochan, L. Henry, F. von Delft, T. D. W. Claridge, U. Oppermann, M. A. McDonough, C. J. Schofield, Chem. Biol. 2010, 17, 1316-1324.

[52] A. H. K. Al Temimi, B. J. G. E. Pieters, Y. V. Reddy, P. B. White, J. Mecinovic, Chem. Commun. 2016, 52, 1284912852.

[53] J. A. G. Kamps, A. Khan, H. Choi, R. K. Lesniak, J. Brem, A. M. Rydzik, M. A. McDonough, C. J. Schofield, T. D. W. Claridge, J. Mecinović, Chem. Eur. J. 2015, 22, 1270-1276.

[54] A. M. Rydzik, I. K. H. Leung, G. T. Kochan, M. A. McDonough, T. D. W. Claridge, C. J. Schofield, Angew. Chemie Int. Ed. 2014, 53, 10925-10927.

[55] L. Henry, I. K. H. Leung, T. D. W. Claridge, C. J. Schofield, Bioorg. Med. Chem. Lett. 2012, 22, 4975-4978.

[56] G. L. Wang, G. L. Semenza, Proc. Natl. Acad. Sci. 1993, 90, 4304 LP-4308.

[57] W. G. Kaelin Jr., P. J. Ratcliffe, Mol. Cell 2008, 30, 393402.
[58] G. L. Semenza, Trends Mol. Med. 2001, 7, 345-50.

[59] C. J. Schofield, P. J. Ratcliffe, Nat. Rev. Mol. Cell Biol. 2004, 5, 343.

[60] C. J. Schofield, P. J. Ratcliffe, Biochem. Biophys. Res. Commun. 2005, 338, 617-626.

[61] S. E. Wilkins, E. Flashman, J. S. Scotti, R. J. Hopkinson, R. Chowdhury, C. J. Schofield, in 2-Oxoglutarate-Dependent Oxygenases, The Royal Society Of Chemistry, 2015, pp. 169-209.

[62] J.-H. Min, H. Yang, M. Ivan, F. Gertler, W. G. Kaelin, N. P. Pavletich, Science 2002, 296, 1886-1889.

[63] W.-C. Hon, M. I. Wilson, K. Harlos, T. D. W. Claridge, C. J. Schofield, C. W. Pugh, P. H. Maxwell, P. J. Ratcliffe, D. I. Stuart, E. Y. Jones, Nature 2002, 417, 975.

[64] R. K. Bruick, S. L. McKnight, Science 2001, 294, 13371340.

[65] A. C. R. Epstein, J. M. Gleadle, L. A. McNeill, K. S. Hewitson, J. O'Rourke, D. R. Mole, M. Mukherji, E. Metzen, M. I. Wilson, A. Dhanda, et al., Cell 2001, 107, 43-54.

[66] P. Jaakkola, D. R. Mole, Y.-M. Tian, M. I. Wilson, J. Gielbert, S. J. Gaskell, A. von Kriegsheim, H. F. Hebestreit, M. Mukherji, C. J. Schofield, et al., Science 2001, 292, 468-472.

[67] P. Koivunen, M. Hirsila, V. A. Gunzler, K. I. Kivirikko, J. Myllyharju, J. Biol. Chem. 2003, 279, 9899-9904.

[68] E. Flashman, L. M. Hoffart, R. B. Hamed, J. M. Bollinger, C. Krebs, C. J. Schofield, FEBS J. 2010, 277, 4089-99.

D. Ehrismann, E. Flashman, D. N. Genn, N. Mathioudakis, K. S. Hewitson, P. J. Ratcliffe, C. J. Schofield, Biochem. J. 2007, 401, 227 LP-234.

[70] L. A. McNeill, E. Flashman, M. R. G. Buck, K. S. Hewitson, I. J. Clifton, G. Jeschke, T. D. W. Claridge, D. Ehrismann, N. J. Oldham, C. J. Schofield, Mol. BioSyst. 2005, 1, 321324.

[71] H. Tarhonskaya, A. P. Hardy, E. A. Howe, N. D. Loik, H. B. Kramer, J. S. O. McCullagh, C. J. Schofield, E. Flashman, J. Biol. Chem. 2015, 290, 19726-42.

[72] M. A. McDonough, V. Li, E. Flashman, R. Chowdhury, C. Mohr, B. M. Lienard, J. Zondlo, N. J. Oldham, I. J. Clifton, J. Lewis, et al., Proc Natl Acad Sci U S A 2006, 103, 98149819.

[73] R. J. Appelhoff, Y.-M. Tian, R. R. Raval, H. Turley, A. L. Harris, C. W. Pugh, P. J. Ratcliffe, J. M. Gleadle, J. Biol. Chem. 2004, 279, 28458-65.

[74] M. I. Abboud, T. E. McAllister, I. K. H. Leung, R. Chowdhury, C. Jorgensen, C. Domene, J. Mecinovic, K. Lippl, R. L. Hancock, R. J. Hopkinson, et al., Chem. Commun. 2018, 54, 3130-3133.

[75] C. Loenarz, M. L. Coleman, A. Boleininger, B. Schierwater, P. W. H. Holland, P. J. Ratcliffe, C. J. Schofield, EMBO Rep. 2011, 12, 63 LP-70.

[76] M. C. Chan, N. E. llott, J. Schödel, D. Sims, A. Tumber, K. Lippl, D. R. Mole, C. W. Pugh, P. J. Ratcliffe, C. P. Ponting, et al., J. Biol. Chem. 2016, 291, 20661-73.

[77] P. H. Maxwell, K.-U. Eckardt, Nat. Rev. Nephrol. 2015, 12, 157.

[78] M. C. Chan, J. P. Holt-Martyn, C. J. Schofield, P. J. Ratcliffe, Mol. Aspects Med. 2016, 47-48, 54-75.

[79] P. C. Mahon, K. Hirota, G. L. Semenza, Genes Dev. 2001, 15, 2675-86

[80] D. Lando, D. J. Peet, J. J. Gorman, D. A. Whelan, M. L. Whitelaw, R. K. Bruick, Genes Dev. 2002, 16, 1466-1471.

[81] D. Lando, D. J. Peet, D. A. Whelan, J. J. Gorman, M. L. Whitelaw, Science 2002, 295, 858-61.

[82] C. E. Dann 3rd, R. K. Bruick, J. Deisenhofer, Proc Natl Acad Sci U S A 2002, 99, 15351-15356.

[83] K. S. Hewitson, L. A. McNeill, M. V Riordan, Y.-M. Tian, A. N. Bullock, R. W. Welford, J. M. Elkins, N. J. Oldham, S. Bhattacharya, J. M. Gleadle, et al., J. Biol. Chem. 2002. 277, 26251-5. 
[84] Y.-M. Tian, K. Yeoh, M. K. Lee, T. Eriksson, B. M. Kessler, H. B. Kramer, M. J. Edelmann, C. Willam, C. W. Pugh, C. J. Schofield, et al., J. Biol. Chem. 2011, 286, 13041-51.

[85] M. A. McDonough, L. A. McNeill, M. Tilliet, C. A Papamicaël, Q.-Y. Chen, B. Banerji, K. S. Hewitson, C. J. Schofield, J Am Chem Soc 2005, 127, 7680-7681.

[86] N. Zhang, Z. Fu, S. Linke, J. Chicher, J. J. Gorman, D. Visk, G. G. Haddad, L. Poellinger, D. J. Peet, F. Powell, et al., Cell Metab. 2010, 11, 364-378.

[87] I. P. Stolze, Y.-M. Tian, R. J. Appelhoff, H. Turley, C. C. Wykoff, J. M. Gleadle, P. J. Ratcliffe, J. Biol. Chem. 2004, $279,42719-25$

[88] F. Dayan, D. Roux, M. C. Brahimi-Horn, J. Pouyssegur, N. M. Mazure, Cancer Res. 2006, 66, 3688-3698.

[89] N. C. Warshakoon, S. Wu, A. Boyer, R. Kawamoto, J. Sheville, R. T. Bhatt, S. Renock, K. Xu, M. Pokross, S. Zhou, et al., Bioorg. Med. Chem. Lett. 2006, 16, 56165620 .

[90] D. R. Mole, I. Schlemminger, L. A. McNeill, K. S. Hewitson, C. W. Pugh, P. J. Ratcliffe, C. J. Schofield, Bioorg. Med. Chem. Lett. 2003, 13, 2677-2680.

[91] J. M. Kaplan, N. Sharma, S. Dikdan, Int. J. Mol. Sci. 2018, 19.

[92] L. Yan, V. J. Colandrea, J. J. Hale, Expert Opin Ther Pat 2010, 20, 1219-1245.

[93] C. E. Snell, H. Turley, A. McIntyre, D. Li, M. Masiero, C. J. Schofield, K. C. Gatter, A. L. Harris, F. Pezzella, PLoS One 2014, 9, 1-9.

[94] L. Schito, G. L. Semenza, Trends in Cancer 2016, 2, 758 770.

[95] P. J. Pollard, C. Loenarz, D. R. Mole, M. A. McDonough, J. M. Gleadle, C. J. Schofield, P. J. Ratcliffe, Biochem. J. 2008, 416, 387-394.

[96] R. L. Hancock, K. Dunne, L. J. Walport, E. Flashman, A. Kawamura, Epigenomics 2015, 7, 791-811.

[97] T. Laukke, C. J. Mariani, T. Ihantola, J. Z. Cao, J. Hokkanen, W. G. Kaelin Jr., L. A. Godley, P. Koivunen, J. Biol. Chem. 2016, 291, 4256-65.

[98] R. L. Hancock, N. Masson, K. Dunne, E. Flashman, A Kawamura, ACS Chem. Biol. 2017, 12, 1011-1019.

[99] S. Beyer, M. M. Kristensen, K. S. Jensen, J. V Johansen, P. Staller, J. Biol. Chem. 2008, 283, 36542-52.

[100] E. M. Sánchez-Fernández, H. Tarhonskaya, K. Al-Qahtani, R. J. Hopkinson, J. S. O. McCullagh, C. J. Schofield, E. Flashman, Biochem. J. 2013, 449, 491-6.

[101] B. W. Wong, A. Kuchnio, U. Bruning, P. Carmeliet, Trends Biochem. Sci. 2013, 38, 3-11.

[102] C. C. Lawrence, W. J. Sobey, R. A. Field, J. E. Baldwin, C. J. Schofield, Biochem. J. 1996, 313, 185-191.

[103] I. J. Clifton, L. C. Hsueh, J. E. Baldwin, K. Harlos, C. J. Schofield, Eur. J. Biochem. 2001, 268, 6625-6636.

[104] K. L. Gorres, R. T. Raines, Crit. Rev. Biochem. Mol. Biol. 2010, 45, 106-124.

[105] Y. Xu, K. M. Brown, Z. A. Wang, H. van der Well, C. Teygong, D. Zhang, I. J. Blader, C. M. West, J. Biol. Chem. 2012, 287, 25098-110.

[106] K. Rahman, P. Zhao, M. Mandalasi, H. van der Wel, L. Wells, I. J. Blader, C. M. West, J. Biol. Chem. 2016, 291, 4268-80.

[107] C. M. West, H. van der Wel, I. J. B. T.-M. in E. Blader, in Funct. Glycomics, Academic Press, 2006, pp. 389-404.

[108] J. S. Scotti, I. K. Leung, W. Ge, M. A. Bentley, J. Paps, H. Kramer, J. Lee, W. Aik, H. Choi, S. M. Paulsen, et al., Proc Natl Acad SciU S A 2014, 111, 13331-6.

[109] B. Bleijlevens, T. Shivarattan, E. Flashman, Y. Yang, P. J. Simpson, P. Koivisto, B. Sedgwick, C. J. Schofield, S. J. Matthews, EMBO Rep. 2008, 9, 872-877.

[110] R. S. Singleton, P. Liu-Yi, F. Formenti, W. Ge, R. Sekirnik, R. Fischer, J. Adam, P. J. Pollard, A. Wolf, A. Thalhammer, et al., Proc Natl Acad Sci U S A 2014, 111, 4031-4036.
[111] M. J. Katz, J. M. Acevedo, C. Loenarz, D. Galagovsky, P. Liu-Yi, M. Perez-Pepe, A. Thalhammer, R. Sekirnik, W. Ge, M. Melani, et al., Proc Natl Acad Sci U S A 2014, 111, 4025-4030.

[112] C. Loenarz, R. Sekirnik, A. Thalhammer, W. Ge, E. Spivakovsky, M. M. Mackeen, M. A. McDonough, M. E. Cockman, B. M. Kessler, P. J. Ratcliffe, et al., Proc Natl Acad SciU S A 2014, 111, 4019-4024.

[113] S. Horita, J. S. Scotti, C. Thinnes, Y. S. MottaghiTaromsari, A. Thalhammer, W. Ge, W. Aik, C. Loenarz, C J. Schofield, M. A. McDonough, Structure 2015, 23, 639652.

[114] H. S. Kim, H. L. Kim, K. H. Kim, D. J. Kim, S. J. Lee, J. Y. Yoon, H. J. Yoon, H. Y. Lee, S. B. Park, S.-J. Kim, et al., Nucleic Acids Res. 2010, 38, 2099-2110.

[115] K. Saito, N. Adachi, H. Koyama, M. Matsushita, FEBS Lett. n.d., $584,3340-3347$.

[116] S. J. Clasen, W. Shao, H. Gu, P. J. Espenshade, Elife 2017, 6, e28563

[117] B. T. Hughes, P. J. Espenshade, EMBO J. 2008, 27, 14911501.

[118] B. Schmierer, B. Novak, C. Schofield, BMC Syst. Biol. 2010, 4, 139.

[119] R. S. Singleton, D. C. Trudgian, R. Fischer, B. M. Kessler, P. J. Ratcliffe, M. E. Cockman, J. Biol. Chem. 2011, 286, 33784-94.

[120] D. A. Walsh, D. B. Glass, R. D. Mitchell, Curr. Opin. Cell Biol. 1992, 4, 241-251.

[121] J. M. Elkins, K. S. Hewitson, L. A. McNeill, J. F. Seibel, I. Schlemminger, C. W. Pugh, P. J. Ratcliffe, C. J. Schofield, J. Biol. Chem. 2003, 278, 1802-6.

[122] C. Lee, S. J. Kim, D. G. Jeong, S. M. Lee, S. E. Ryu, J. Biol. Chem. 2003, 278, 7558-7563.

[123] P. M. Clissold, C. P. Ponting, Trends Biochem. Sci. 2001 26, 7-9.

[124] M. E. Cockman, D. E. Lancaster, I. P. Stolze, K. S Hewitson, M. a McDonough, M. L. Coleman, C. H. Coles, X. Yu, R. T. Hay, S. C. Ley, et al., Proc. Natl. Acad. Sci. U. S. A. 2006, 103, 14767-72.

[125] M. Yang, A. P. Hardy, R. Chowdhury, N. D. Loik, J. S. Scotti, J. S. McCullagh, T. D. Claridge, M. A. McDonough, W. Ge, C. J. Schofield, Angew. Chem. Int. Ed. Engl. 2013, 52, 1700-1704.

[126] M. Yang, R. Chowdhury, W. Ge, R. B. Hamed, M. A McDonough, T. D. Claridge, B. M. Kessler, M. E. Cockman, P. J. Ratcliffe, C. J. Schofield, FEBS J. 2011, 278, 10861097.

[127] M. E. Cockman, J. D. Webb, P. J. Ratcliffe, Ann. N. Y. Acad. Sci. 2009, 1177, 9-18.

[128] M. L. Coleman, P. J. Ratcliffe, Curr. Pharm. Des. 2009, 15, 3904-3907.

[129] J. Li, A. Mahajan, M. D. Tsai, Biochemistry 2006, 45, 15168-15178.

[130] M. L. Coleman, M. A. McDonough, K. S. Hewitson, C Coles, J. Mecinovic, M. Edelmann, K. M. Cook, M. E. Cockman, D. E. Lancaster, B. M. Kessler, et al., J. Biol. Chem. 2007, 282, 24027-38.

[131] X. Zheng, S. Linke, J. M. Dias, X. Zheng, K. Gradin, T. P. Wallis, B. R. Hamilton, M. Gustafsson, J. L. Ruas, S. Wilkins, et al., Proc. Natl. Acad. Sci. 2008, 105, 3368-3373.

[132] L. Kelly, M. A. McDonough, M. L. Coleman, P. J. Ratcliffe, C. J. Schofield, Mol. Biosyst. 2009, 5, 52-8.

[133] A. P. Hardy, I. Prokes, L. Kelly, I. D. Campbell, C. J. Schofield, J. Mol. Biol. 2009, 392, 994-1006.

[134] M. Yang, R. Chowdhury, W. Ge, R. B. Hamed, M. A McDonough, T. D. W. Claridge, B. M. Kessler, M. E. Cockman, P. J. Ratcliffe, C. J. Schofield, FEBS J. 2011, 278, 1086-97.

[135] M. Yang, W. Ge, R. Chowdhury, T. D. Claridge, H. B. Kramer, B. Schmierer, M. A. McDonough, L. Gong, B. M. 
Kessler, P. J. Ratcliffe, et al., J. Biol. Chem. 2011, 286, 7648-7660.

[136] M. E. Cockman, J. D. Webb, H. B. Kramer, B. M. Kessler, P. J. Ratcliffe, Mol. Cell. Proteomics 2009, 8, 535-46.

[137] S. E. Wilkins, J. Hyvärinen, J. Chicher, J. J. Gorman, D. J. Peet, R. L. Bilton, P. Koivunen, Int. J. Biochem. Cell Biol. 2009, 41, 1563-1571.

[138] S. E. Wilkins, S. Karttunen, R. J. Hampton-Smith, I. Murchland, A. Chapman-Smith, D. J. Peet, J. Biol. Chem. 2012, 287, 8769-81.

[139] D. E. Lancaster, L. A. McNeill, M. A. McDonough, R. T. Aplin, K. S. Hewitson, C. W. Pugh, P. J. Ratcliffe, C. J. Schofield, Biochem. J. 2004, 383, 429-37.

[140] J. R. Whetstine, A. Nottke, F. Lan, M. Huarte, S. Smolikov, Z. Chen, E. Spooner, E. Li, G. Zhang, M. Colaiacovo, et al., Cell 2006, 125, 467-481.

[141] Y. Tsukada, J. Fang, H. Erdjument-Bromage, M. E. Warren, C. H. Borchers, P. Tempst, Y. Zhang, Nature 2006, 439, 811-6.

[142] R. J. Klose, E. M. Kallin, Y. Zhang, Nat. Rev. Genet. 2006, 7, 715-727.

[143] X. Cheng, R. C. Trievel, in 2-Oxoglutarate-Dependent Oxygenases, The Royal Society Of Chemistry, 2015, pp. 210-245.

[144] W. K. Paik, S. Kim, Biochem. Biophys. Res. Commun. 1973, 51, 781-788.

[145] E. Metzger, M. Wissmann, N. Yin, J. M. Muller, R. Schneider, A. H. F. M. Peters, T. Gunther, R. Buettner, R. Schule, Nature 2005, 437, 436-439.

[146] Y. Shi, F. Lan, C. Matson, P. Mulligan, J. R. Whetstine, P. A. Cole, R. A. Casero, Cell 2004, 119, 941-953.

[147] L. J. Walport, R. J. Hopkinson, C. J. Schofield, Curr. Opin. Chem. Biol. 2012, 16, 525-34.

[148] P. O. Falnes, R. F. Johansen, E. Seeberg, Nature 2002 419, 178-182.

[149] S. C. Trewick, T. F. Henshaw, R. P. Hausinger, T. Lindahl, B. Sedgwick, Nature 2002, 419, 174.

[150] C. Yi, G. Jia, G. Hou, Q. Dai, W. Zhang, G. Zheng, X. Jian, C. G. Yang, Q. Cui, C. He, Nature 2010, 468, 330-333.

[151] Y. Fu, G. Jia, X. Pang, R. N. Wang, X. Wang, C. J. Li, S. Smemo, Q. Dai, K. A. Bailey, M. A. Nobrega, et al., Nat. Commun. 2013, 4, 2-9.

[152] S. Shishodia, D. Zhang, A. H. El-Sagheer, T. Brown, T. D. W. Claridge, C. J. Schofield, R. J. Hopkinson, Org. Biomol. Chem. 2018, 16, 4021-4032.

[153] R. J. Hopkinson, L. J. Walport, M. Münzel, N. R. Rose, T. J. Smart, A. Kawamura, T. D. W. Claridge, C. J. Schofield, Angew. Chem. Int. Ed. Engl. 2013, 52, 7709-13.

[154] S. Markolovic, T. M. Leissing, R. Chowdhury, S. E. Wilkins, X. Lu, C. J. Schofield, Curr. Opin. Struct. Biol. 2016, 41, 62-72.

[155] S. Markolovic, Q. Zhuang, S. E. Wilkins, C. D. Eaton, M. I. Abboud, M. J. Katz, H. E. McNeil, R. K. Leśniak, C. Hall, W. B. Struwe, et al., Nat. Chem. Biol. 2018, 14, 688-695.

[156] T. Feng, A. Yamamoto, S. E. Wilkins, E. Sokolova, L. A. Yates, M. Munzel, P. Singh, R. J. Hopkinson, R. Fischer, M. E. Cockman, et al., Mol. Cell 2014, 53, 645-654.

[157] C. J. Webby, A. Wolf, N. Gromak, M. Dreger, H. Kramer, B. M. Kessler, M. L. Nielsen, C. Schmitz, D. S. Butler, J. R. Yates 3rd., et al., Science 2009, 325, 90-93.

[158] T. Jiang, X. Zhou, K. Taghizadeh, M. Dong, P. C. Dedon, Proc. Natl. Acad. Sci. 2007, 104, 60 LP-65.

[159] B. C. Smith, J. M. Denu, Biochim. Biophys. Acta 2009, $1789,45-57$.

[160] W. Ge, A. Wolf, T. Feng, C. Ho, R. Sekirnik, A. Zayer, N. Granatino, M. E. Cockman, C. Loenarz, N. D. Loik, et al., Nat. Chem. Biol. 2012, 8, 960-2.

[161] R. Chowdhury, R. Sekirnik, N. C. Brissett, T. Krojer, C. H. Ho, S. S. Ng, I. J. Clifton, W. Ge, N. J. Kershaw, G. C. Fox, et al., Nature 2014, 510, 422-426.
[162] R. Sekirnik, S. E. Wilkins, J. Bush, H. Tarhonskaya, M. Münzel, A. Hussein, E. Flashman, S. Mohammed, M. A. McDonough, C. Loenarz, et al., Extremophiles 2018, 22, 553-562.

[163] S. E. Wilkins, S. Islam, J. M. Gannon, S. Markolovic, R. J. Hopkinson, W. Ge, C. J. Schofield, R. Chowdhury, Nat. Commun. 2018, 9, 1180.

[164] B. Chang, Y. Chen, Y.-F. Zhao, R. K. Bruick, Science 2007 318, 444-447.

[165] W. Liu, Q. Ma, K. Wong, W. Li, K. Ohgi, J. Zhang, A. K. Aggarwal, M. G. Rosenfeld, Cell 2013, 155, 1581-95.

[166] A. Böttger, M. S. Islam, R. Chowdhury, C. J. Schofield, A. Wolf, Biochem. J. 2015, 468, 191 LP-202.

[167] M. Mantri, T. Krojer, E. A. Bagg, C. J. Webby, D. S. Butler, G. Kochan, K. L. Kavanagh, U. Oppermann, M. A. McDonough, C. J. Schofield, J. Mol. Biol. 2010, 401, 211222.

[168] M. Mantri, N. D. Loik, R. B. Hamed, T. D. W. Claridge, J. S. O. McCullagh, C. J. Schofield, ChemBioChem 2011, 12, $531-534$

[169] M. Unoki, A. Masuda, N. Dohmae, K. Arita, M. Yoshimatsu, Y. Iwai, Y. Fukui, K. Ueda, R. Hamamoto, M. Shirakawa, et al., J. Biol. Chem. 2013, 288, 6053-62.

[170] J.-N. Boeckel, V. Guarani, M. Koyanagi, T. Roexe, A Lengeling, R. T. Schermuly, P. Gellert, T. Braun, A. Zeiher, S. Dimmeler, Proc. Natl. Acad. Sci. U. S. A. 2011, 108, 3276-3281.

[171] A. Noma, R. Ishitani, M. Kato, A. Nagao, O. Nureki, T. Suzuki, J. Biol. Chem. 2010, 285, 34503-7.

[172] M. Kato, Y. Araiso, A. Noma, A. Nagao, T. Suzuki, R. Ishitani, O. Nureki, Nucleic Acids Res. 2011, 39, 15761585.

[173] L. M. Iyer, S. Abhiman, R. F. de Souza, L. Aravind, Nucleic Acids Res. 2010, 38, 5261-5279.

[174] F. De Santa, V. Narang, Z. H. Yap, B. K. Tusi, T. Burgold, L. Austenaa, G. Bucci, M. Caganova, S. Notarbartolo, S. Casola, et al., EMBO J. 2009, 28, 3341-52.

[175] H. Faralli, C. Wang, K. Nakka, A. Benyoucef, S. Sebastian, L. Zhuang, A. Chu, C. G. Palii, C. Liu, B. Camellato, et al., J. Clin. Invest. 2016, 126, 1555-1565.

[176] L. Li, C. Greer, R. N. Eisenman, J. Secombe, PLOS Genet. 2010, 6, 1-11.

[177] E. Dimitrova, A. H. Turberfield, R. J. Klose, EMBO Rep. 2015, 16, 1620-39.

[178] J. Murn, Y. Shi, Nat. Rev. Mol. Cell Biol. 2017, DOI 10.1038/nrm.2017.35.

[179] J. R. Horton, A. K. Upadhyay, H. H. Qi, X. Zhang, Y. Shi, X. Cheng, Nat. Struct. Mol. Biol. 2010, 17, 38-43.

[180] D. Kleine-Kohlbrecher, J. Christensen, J. Vandamme, I. Abarrategui, M. Bak, N. Tommerup, X. Shi, O. Gozani, J. Rappsilber, A. E. Salcini, Mol. Cell 2010, 38, 165-178.

[181] C. Loenarz, W. Ge, M. L. Coleman, N. R. Rose, C. D. O. Cooper, R. J. Klose, P. J. Ratcliffe, C. J. Schofield, Hum. Mol. Genet. 2010, 19, 217-22.

[182] W. Feng, M. Yonezawa, Y. Jung, T. Jenuwein, I. Grummt, J. Ye, Nat. Struct. Mol. Biol. 2010, 17, 445-50.

[183] H. H. Qi, M. Sarkissian, G.-Q. Hu, Z. Wang, A. Bhattacharjee, D. B. Gordon, M. Gonzales, F. Lan, P. P. Ongusaha, M. Huarte, et al., Nature 2010, 466, 503-7.

[184] J. F. Couture, E. Collazo, P. A. Ortiz-Tello, J. S. Brunzelle, R. C. Trievel, Nat. Struct. Mol. Biol. 2007, 14, 689-695.

[185] S. S. Ng, K. L. Kavanagh, M. A. McDonough, D. Butler, E. S. Pilka, B. M. Lienard, J. E. Bray, P. Savitsky, C. Gileadi, F. Von Delft, et al., Nature 2007, 448, 87-91.

[186] S. T. Williams, L. J. Walport, R. J. Hopkinson, S. K. Madden, R. Chowdhury, C. J. Schofield, A. Kawamura, S. T. Williams, L. J. Walport, R. J. Hopkinson, et al., Epigenetics 2015, 9, 1596-1603.

[187] Z. Chen, J. Zang, J. Whetstine, X. Hong, F. Davrazou, T. G Kutateladze, M. Simpson, Q. Mao, C. H. Pan, S. Dai, et al., 
Cell 2006, 125, 691-702.

[188] L. Hillringhaus, W. W. Yue, N. R. Rose, S. S. Ng, C. Gileadi, C. Loenarz, S. Bello, J. E. Bray, C. J. Schofield, U. Oppermann, J. Biol. Chem. 2011, 286, 41616-41625.

[189] G. W. Langley, A. Brinkø, M. Münzel, L. J. Walport, C. J. Schofield, R. J. Hopkinson, ACS Chem. Biol. 2016, 11, 755-62.

[190] L. Walport, R. Hopkinson, R. Chowdhury, R. Schiller, W. Ge, A. Kawamura, C. Schofield, Nat. Commun. 2016, 7 , 11974.

[191] S. Li, S. Ali, X. Duan, S. Liu, J. Du, C. Liu, H. Dai, M. Zhou, L. Zhou, L. Yang, et al., Cell Rep. 2018, 23, 389-403.

[192] M. A. Kurowski, A. S. Bhagwat, G. Papaj, J. M. Bujnicki, BMC Genomics 2003, 4, 48.

[193] C. Yi, C. He, Cold Spring Harb. Perspect. Biol. 2013, 5, a012575.

[194] L. Sanchez-Pulido, M. A. Andrade-Navarro, BMC Biochem. 2007, 8, 6-11.

[195] L. Aravind, D. Zhang, L. M. Iyer, in 2-OxoglutarateDependent Oxygenases, The Royal Society Of Chemistry, 2015, pp. 289-308.

[196] T. A. Muller, R. P. Hausinger, in 2-Oxoglutarate-Dependent Oxygenases, The Royal Society Of Chemistry, 2015, pp. 246-262.

[197] J. Ringvoll, L. M. Nordstrand, C. B. Vagbo, V. Talstad, K. Reite, P. A. Aas, K. H. Lauritzen, N. B. Liabakk, A. Bjork, R. W. Doughty, et al., EMBO J. 2006, 25, 2189-2198.

[198] T. Gerken, C. A. Girard, Y.-C. L. Tung, C. J. Webby, V. Saudek, K. S. Hewitson, G. S. H. Yeo, M. A. McDonough, S. Cunliffe, L. A. McNeill, et al., Science 2007, 318, 14691472.

[199] G. Jia, C.-G. Yang, S. Yang, X. Jian, C. Yi, Z. Zhou, C. He, FEBS Lett. 2008, 582, 3313-3319.

[200] G. Jia, Y. Fu, Q. Dai, G. Zheng, Y. Yang, C. Yi, T. Lindahl, T. Pan, Y.-G. Yang, C. He, Nat. Chem. Biol. 2011, 7, 885887.

[201] G. Zheng, J. A. Dahl, Y. Niu, P. Fedorcsak, C.-M. Huang, C. J. Li, C. B. Vågbø, Y. Shi, W.-L. Wang, S.-H. Song, et al., Mol. Cell 2013, 49, 18-29.

[202] B. S. Zhao, I. A. Roundtree, C. He, Nat. Rev. Mol. Cell Biol. 2016, 18, 31-42.

[203] M. Tahiliani, K. P. Koh, Y. Shen, W. A. Pastor, H Bandukwala, Y. Brudno, S. Agarwal, L. M. Iyer, D. R. Liu, L. Aravind, et al., Science 2009, 324, 930-5.

[204] S. Ito, L. Shen, Q. Dai, S. C. Wu, L. B. Collins, J. A. Swenberg, C. He, Y. Zhang, Science 2011, 333, 1300-3.

[205] Y.-F. He, B.-Z. Li, Z. Li, P. Liu, Y. Wang, Q. Tang, J. Ding, Y. Jia, Z. Chen, L. Li, et al., Science 2011, 333, 1303-7.
[206] L. Shen, C.-X. Song, C. He, Y. Zhang, Annu. Rev. Biochem. 2014, 83, 585-614.

[207] P. Koivunen, T. Laukka, Cell. Mol. Life Sci. 2018, 75, 13391348.

[208] X. Wu, Y. Zhang, Nat. Rev. Genet. 2017, 18, 517-534.

[209] K. Iwan, R. Rahimoff, A. Kirchner, F. Spada, A. S. Schröder, O. Kosmatchev, S. Ferizaj, J. Steinbacher, E. Parsa, M. Müller, et al., Nat. Chem. Biol. 2017, 14, 72

[210] C. Thomas, K. M. Q., M. Markus, R. Martin, S. Fabio, Angew. Chemie Int. Ed. 2017, 57, 4296-4312.

[211] K. D. Rasmussen, K. Helin, Genes Dev. 2016, 30, 733750.

[212] K. S. Hewitson, S. L. Holmes, D. Ehrismann, A. P. Hardy, R. Chowdhury, C. J. Schofield, M. A. McDonough, J. Biol. Chem. 2008, 283, 25971-25978.

[213] D. D. Shah, G. R. Moran, in 2-Oxoglutarate-Dependent Oxygenases, The Royal Society Of Chemistry, 2015, pp. 438-457.

[214] T.-L. Yeh, T. Leissing, M. I. Abboud, C. C. Thinnes, O. Atasoylu, J. P. Holt-Martyn, D. Zhang, A. Tumber, K. Lippl, C. T. Lohans, et al., Chem. Sci. 2017, 8, 7651-7668.

[215] S. Y. Kim, E. G. Yang, Molecules 2015, 20, 20551-20568.

[216] C. C. Thinnes, K. S. England, A. Kawamura, R. Chowdhury, C. J. Schofield, R. J. Hopkinson, Biochim Biophys Acta 2014, DOI 10.1016/j.bbagrm.2014.05.009.

[217] N. R. Rose, E. C. Y. Woon, A. Tumber, L. J. Walport, R. Chowdhury, X. S. Li, O. N. F. King, C. Lejeune, S. S. Ng, T. Krojer, et al., J. Med. Chem. 2012, 55, 6639-43.

[218] E. C. Y. Woon, A. Tumber, A. Kawamura, L. Hillringhaus, W. Ge, N. R. Rose, J. H. Y. Ma, M. C. Chan, L. J. Walport, K. H. Che, et al., Angew. Chemie - Int. Ed. 2012, 51, 16314.

[219] A. Kawamura, M. Münzel, T. Kojima, C. Yapp, B. Bhushan, Y. Goto, A. Tumber, T. Katoh, O. N. F. King, T. Passioura, et al., Nat. Commun. 2017, 8, 14773.

[220] B. Z. Simkhovich, Z. V Shutenko, D. V Meirēna, K. B. Khagi, R. J. Mežapukse, T. N. Molodchina, I. J. Kalvlnsš, E. Lukevics, Biochem. Pharmacol. 1988, 37, 195-202.

[221] A. M. Rydzik, R. Chowdhury, G. T. Kochan, S. T. Williams, M. A. McDonough, A. Kawamura, C. J. Schofield, Chem. Sci. 2014, 5, 1765-1771.

[222] R. J. Hopkinson, C. J. Schofield, Biochemistry 2018, 57, 904-906. 
WILEY-VCH 